\title{
A Methodology to Study High-Speed Pantograph-Catenary Interaction with Realistic Contact Wire Irregularities
}

Yang Song ${ }^{a^{*}}$, Pedro Antunes ${ }^{\mathrm{b}, \mathrm{c}}$, Joao Pombo ${ }^{\mathrm{b}, \mathrm{c}, \mathrm{d}}$, Zhigang Liu ${ }^{\mathrm{e}}$

${ }^{a}$ Department of Structural Engineering, Norwegian University of Science and Technology, Trondheim, 7491, Norway

${ }^{b}$ Institute of Railway Research, University of Huddersfield, Queensgate, Huddersfield, HD1 3DG, UK;

'IDMEC, Instituto Superior Técnico, Universidade de Lisboa, Lisboa, Portugal;

${ }^{d} I S E L$, IPL, Lisboa, Portugal;

${ }^{e}$ School of Electrical Engineering, Southwest Jiaotong University, Chengdu, 610031, China

*Corresponding author: yang.song@ntnu.no 


\title{
A Methodology to Study High-Speed Pantograph-Catenary Interaction with Realistic Contact Wire Irregularities
}

\begin{abstract}
In high-speed rail operations, the irregularity of the overhead system is a typical disturbance that affects the pantograph-catenary interaction performance. The existing methods, which treat the contact wire irregularities as hard spots, overestimate the negative effect of the irregularities on the contact force, leading to conservative results. In this work, a more accurate methodology aiming to include the effect of contact wire irregularities in the assessment of the pantographcatenary dynamic performance is proposed. Measured contact wire irregularity data, collected from the Chinese high-speed network, is added to the initial configuration of the catenary model, through a developed Target Configuration Under Dead-loads (TCUD) method. This approach is used here to investigate the effect of the contact wire irregularities on the contact forces. The results indicate that the catenary imperfections have a direct impact on the pantograph-catenary interaction, leading to an increment of the contact forces amplitude, an increase of their standard deviation and an expansion of the contact forces range. A frequency analysis of the results shows that the contact wire irregularity increases the Power Spectral Density (PSD) peaks of the contact force at specific frequencies relevant to the span length and to the dropper spacing.
\end{abstract}

Keywords: High-Speed Railway; Pantograph-Catenary Interaction; Catenary Irregularities; Shape-Finding; Quality of Current Collection.

\section{Introduction}

In electrified railway systems, the overhead contact line (also called catenary) is constructed along the track, being responsible for transmitting the electric current to the trains via the pantographs installed on the vehicles roof [1]. As illustrated in Figure 1, the electrical current is continuously transmitted from the overhead system to the locomotive through the sliding contact between the catenary and the pantograph. The quality of the current collection is directly determined by the pantograph-catenary interaction performance.

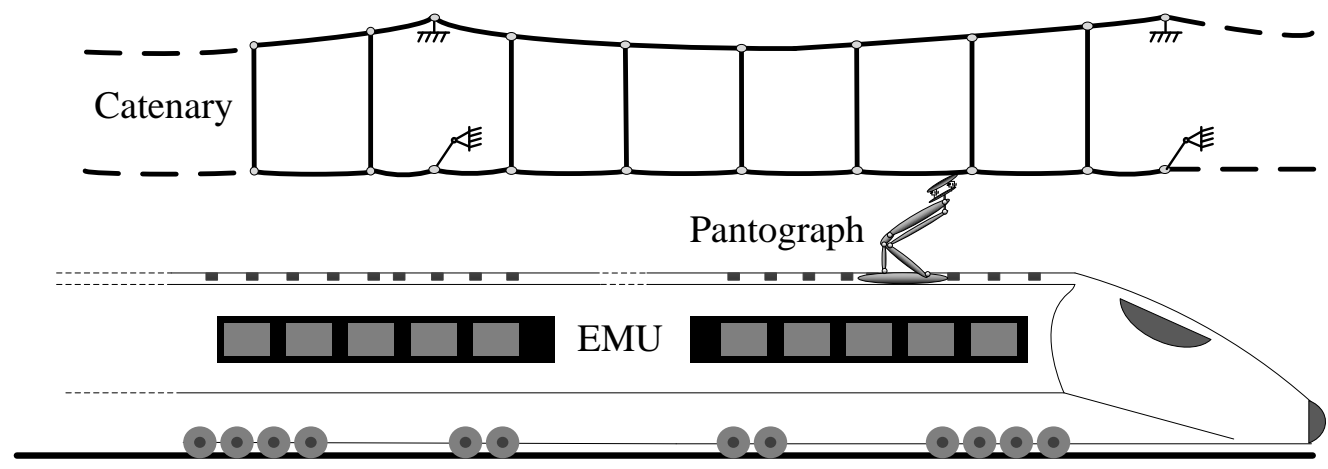

Figure 1. Schematic of a pantograph-catenary system 


\subsection{Problem description}

Generally, the catenary is the most vulnerable part of the railway system as it suffers multiple impacts form the pantographs and is often subjected to unfriendly environmental conditions. These circumstances, together with long-term service, mounting imprecisions and inadequate maintenance, result in the geometric distortion of the catenary with respect to its original design geometry, as shown in Figure 2. As the train speed increases, the influence of the catenary irregularities is gradually noticeable with implications on railway operations. In particular, the vertical irregularities of the contact wire have a direct impact on the dynamic performance of the pantograph collector, which have a significant effect on the quality of current collection.

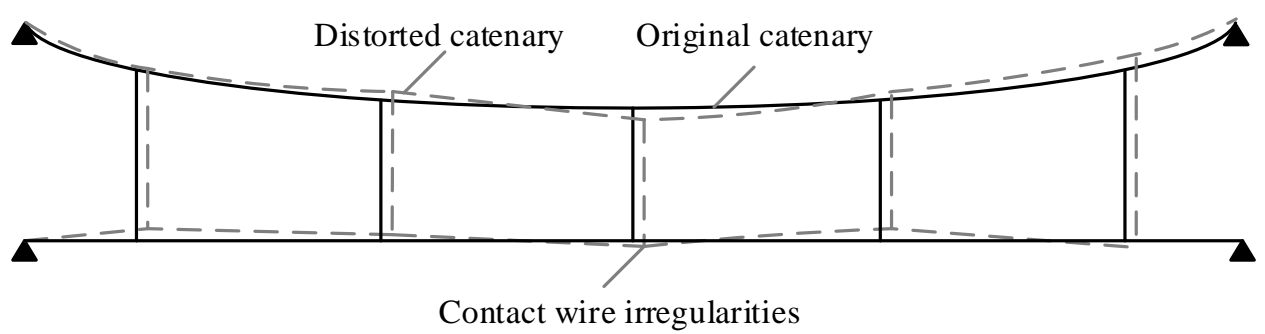

Figure 2. Geometric distortion of a railway catenary

\subsection{Literature review}

Recently, the pantograph-catenary interaction has devoted increasing interest from the scientific community. It is a crucial issue towards enabling faster and more reliable operation of trains, contributing to minimize the number of incidents that cause traffic disruptions and to reduce the maintenance costs of the rolling stock and infrastructure [2]. The catenary is comprised of several tensioned cables, which experience significant prestress. In order to describe the initial configuration of catenary, Arias et al. [3] present a mathematical model of the static pantograph-catenary interaction using linear finite element methods. To deal with the intrinsic nonlinearity, Lopez-Garcia et al. [4] utilize the Newton-Raphson method to find the static solution of the analytical catenary equation. Tur et al. [5] propose a shape-finding method for the initial configuration of catenary based on the Absolute Nodal Coordinate Formulation (ANCF). Using ANCF, Seo. et al. [6] perform a three-large deformation analysis of the multibody pantographcatenary system. Antunes et al. present an alternative method for catenary initialisation based on optimisation methods [7-10]. Song et al. [11-13] introduce a TCUD method to calculate the target configuration of catenary with realistic constraints based on the explicit formulas of cable and truss elements. To reproduce the realistic behaviour of the pantograph, Facchinetti et al. [14] developed a hardware-in-the-loop hybrid simulation based on a real-time catenary model. In these works, the design data is generally utilized to create the catenary model, but the existence of differences between the design and the actual geometry of catenary is acknowledged by Navik and Rouquist [15]. The realistic contact wire commonly exhibits a significant irregularity along the track length. However, besides local defects considered by Antunes et al. [10] and Vesali et al. [16], this variability has not been considered in the initialisation of the catenary. 
The pantograph-catenary system performance is affected by complex service conditions resultant from the high-speed airflow, wind loads, temperature variations, pantograph impact forces and from catenary defects and anomalies [17]. The aerodynamic forces are applied to the pantograph models, and their effects on the contact force are evaluated by Carnevale et al. [18] and Pombo et al. [19]. The behaviour of the catenary under stochastic wind field is analysed by Song et al. [20,21], and the aerodynamic instability of the catenary is investigated by Avila-Sanchez et al. [22]. Based on historical data, the evolution of the contact wire wear is analysed and its effect on the pantograph-catenary contact force is studied by Wang et al. [23]. The effect of train excitations on the pantograph-catenary interaction performance is evaluated by Carnicero et al. [24], Kulkarni et al. [25] and Pombo et al. [26]. The effects of the track irregularities and wind loads are both addressed by Pombo et al. [27] and the multiple pantographs interaction with a high-speed catenary is analysed by the same authors [28-30]. A fully three-dimensional interaction methodology is also developed based on the finite element method, for the catenary [31], and multibody dynamics methods, for the pantograph [3234], integrated via an efficient co-simulation procedure [35-37]. These studies can be conducted in tangential or curved tracks [38]. Other authors devote their attention to the wear of contact wire on the catenary and on the collector strips on the pantograph $[39,40]$.

The study on the effect of the contact wire irregularity is firstly reported by Zhang et al. [41]. Hyeon et al. [42] acknowledge the important implications of the contact wire pre-sag on the dynamic performance of the pantograph-catenary system. Vo Van et al. [43] propose an analytical model to evaluate the contribution of the catenary geometry to the contact forces variation. In early studies, the irregularities in the contact wire are usually represented by an ideal sinusoidal function $[44,45]$. With the development of sensing systems and detection techniques, realistic field data are collected to study the impact of the contact wire irregularities on the pantograph-catenary dynamics [46].

\subsection{Scope and Contribution}

However, in the above-mentioned works, the contact wire irregularities are treated as additional rigid displacements to calculate the contact force. Such an approach requires improvements in order to add the variation of the contact wire height directly into the initial configuration of the catenary. Further investigations are, therefore, necessary in order to assess the effect of contact wire irregularities on the pantograph-catenary interaction forces.

The main aim of this work is to propose a novel methodology to construct catenary models with realistic irregularities and to assess their effect on the pantograph-catenary dynamic performance. The measurement data of contact wire height and the corresponding irregularities are collected from the Chinese high-speed network and its frequency characteristics are analysed. A shape-finding procedure is also implemented here to find the initial configuration of the catenary with irregularities. Then, in order to understand the effect of catenary imperfections on the contact forces, several case studies, at different speeds, are analysed and comparisons with previous methods are performed.

\subsection{Organisation}

In Section 2, the measurement scheme of contact wire irregularity is illustrated and its frequency characteristics is analysed. In Section 3, the finite element model of catenary is described, and the shape-finding method with contact wire height variation is illustrated. In Section 4, the effect of contact wire irregularities on pantograph-catenary 
interaction is evaluated at different speeds, and the comparison with the previous method is performed. The conclusion is drawn in Section 5.

\section{Description of Measurement Data}

The contact wire irregularity data used in this work are collected from the Chinese highspeed network through a contactless detection technique. Figure 3 shows the schematic of a noncontact inspection vehicle running regularly to monitor the static parameters of the catenary. The contact wire height can be obtained through the time of the laser transmitting from the emitter to the camera, corrected with the vibration compensation of the inspection vehicle. The obtained vertical contact wire height on the track is presented in Figure 4. By removing the nominal height of the contact wire, the contact wire irregularities in one catenary section is presented in Figure 5, and its PSD analysis is presented in Figure 6. The PSD peaks appear at the frequencies relevant to the span length, half-span length and the dropper spacing. The contact wire irregularities contribute to the perturbations of the contact force with these dominant frequencies. The spatial frequency components of irregularities higher than the dropper spacing are seemingly relevant to the wear on the contact wire surface. However, these exceed the accuracy range of the measurement equipment, according to its specifications. Taking also into account that the sag of the contact wire between two droppers is purely caused by the gravity, in this work, these irregularly data at higher frequencies is eliminated through filtering before the data is employed to construct the catenary model.

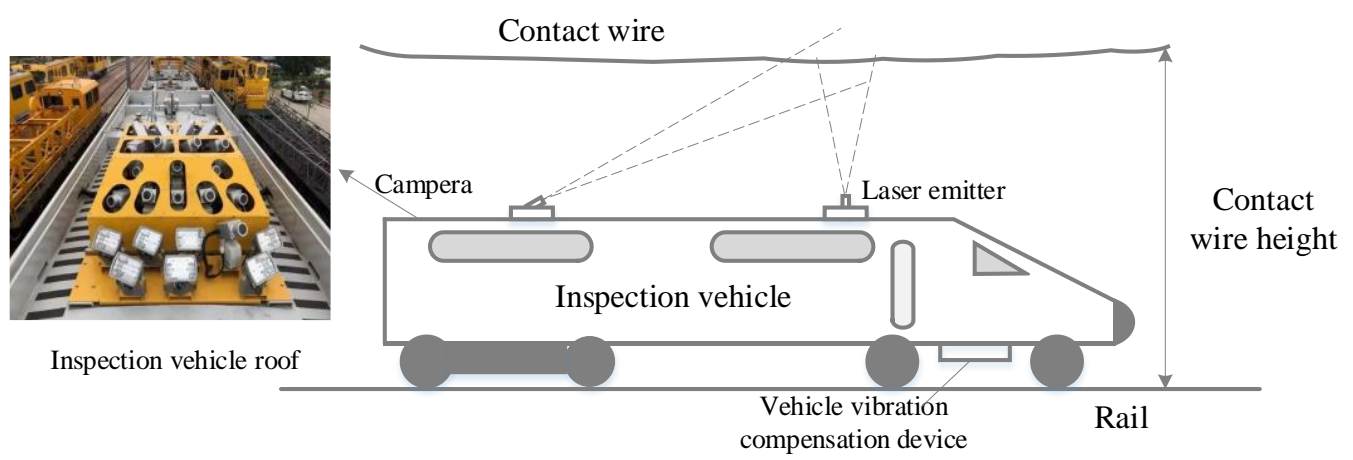

Figure 3. Schematic of a contactless inspection vehicle.

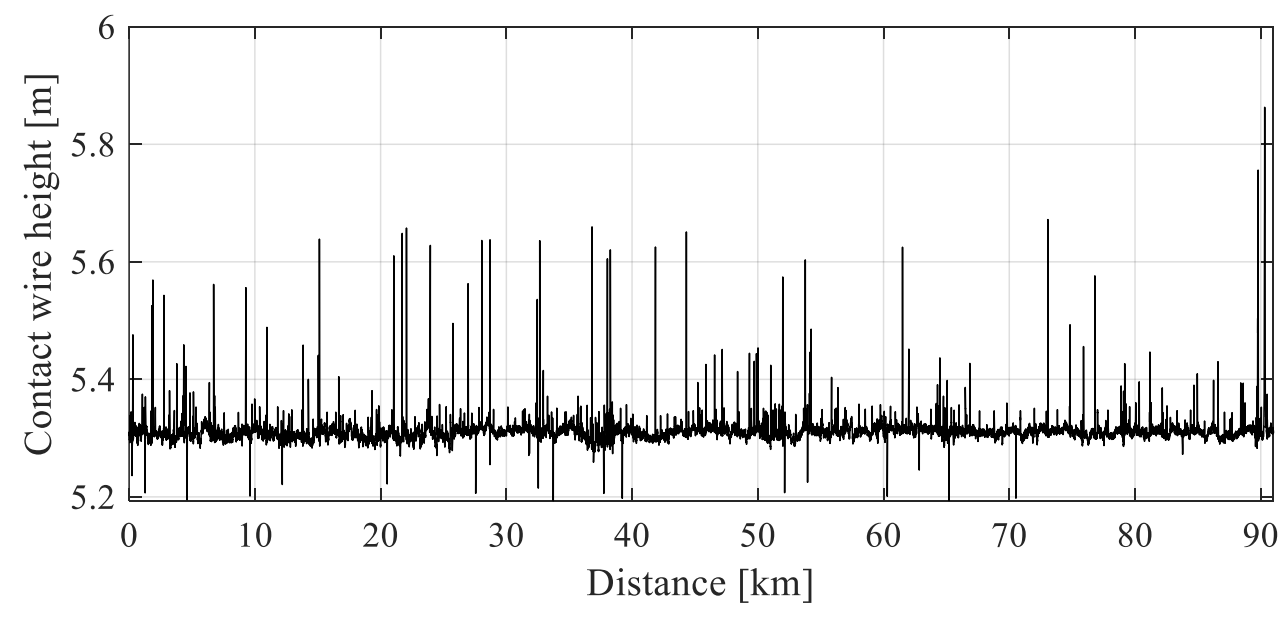

Figure 4. Measured contact wire height data 


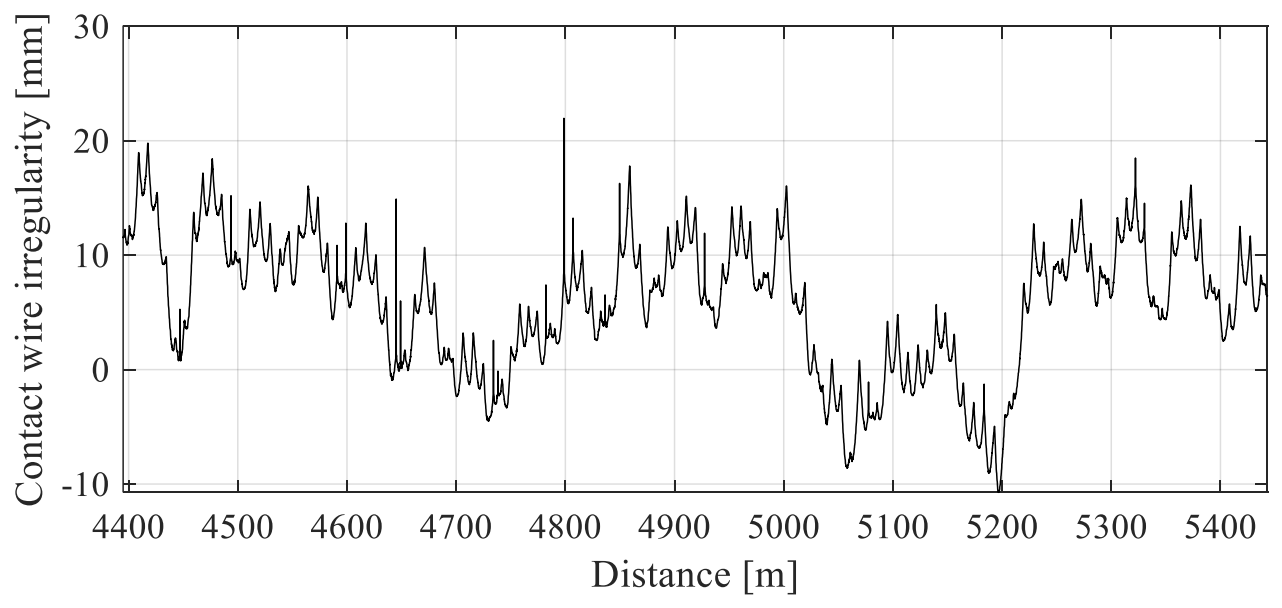

Figure 5. Contact wire irregularities

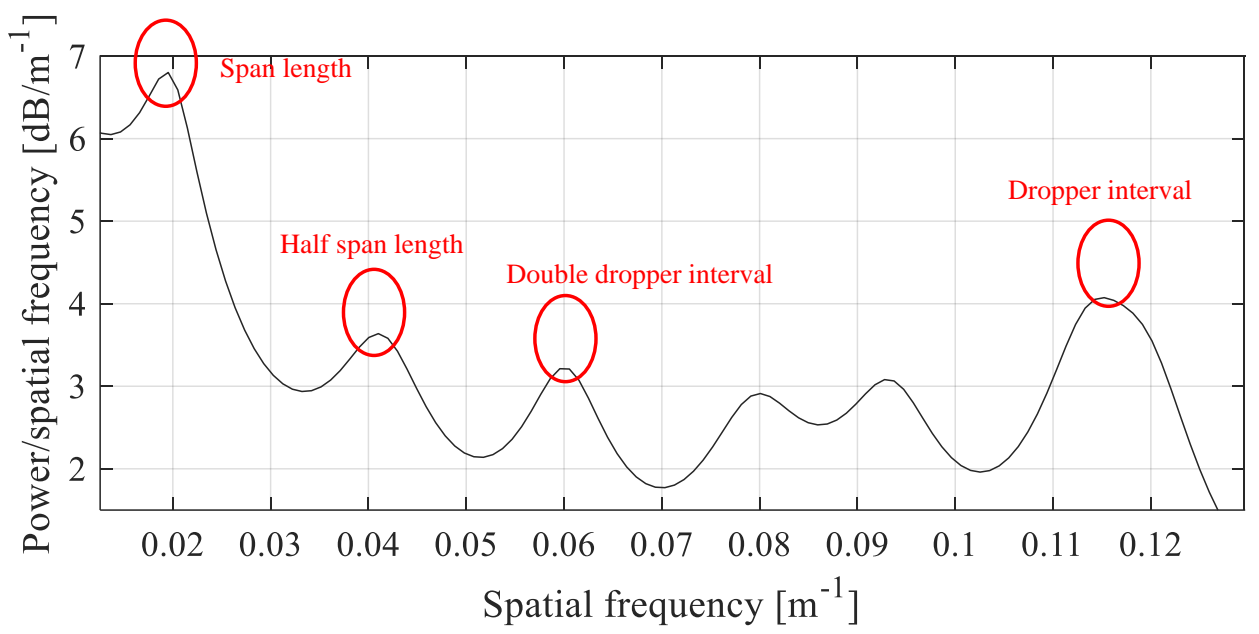

Figure 6. PSD of contact wire irregularities

\section{Catenary Model with Contact Wire Irregularities}

The catenary modelling techniques have been developed in the past decade, which are summarized in [47]. Due to the intrinsic nonlinearity, the finite element method is the most preferred approach to model the catenary, which is used to represent the catenary model in this work. Flexible cable and truss elements are used to model its structural components. The TCUD method is employed to find the initial configuration of the catenary, including when geometric irregularities are considered in the model. This method has been verified against EN 50318 [48], the world benchmark [47], as well as measurement data $[11,49]$.

\subsection{Cable and Truss Elements}

The catenary is generally comprised of four types of components: the contact wire, the messenger wire, the dropper and the steady arm, as depicted in Figure 7. The contact wire is responsible for carrying the electrical current to be collected by the pantograph. The messenger wire and droppers support the contact wire, keeping it at its correct height which may include a specific pre-sag. To adequately describe the nonlinearities of the 
catenary, including the dropper slacking and the geometrical nonlinearity of the contact/messenger wires, the flexible cable element is adopted to model the contact/messenger wire, and the truss element is used to model the dropper and steady arm. The claws on clamps placed in the droppers and steady arms are modelled as lumped masses. In the following, the cable and truss elements used in the catenary model are described.

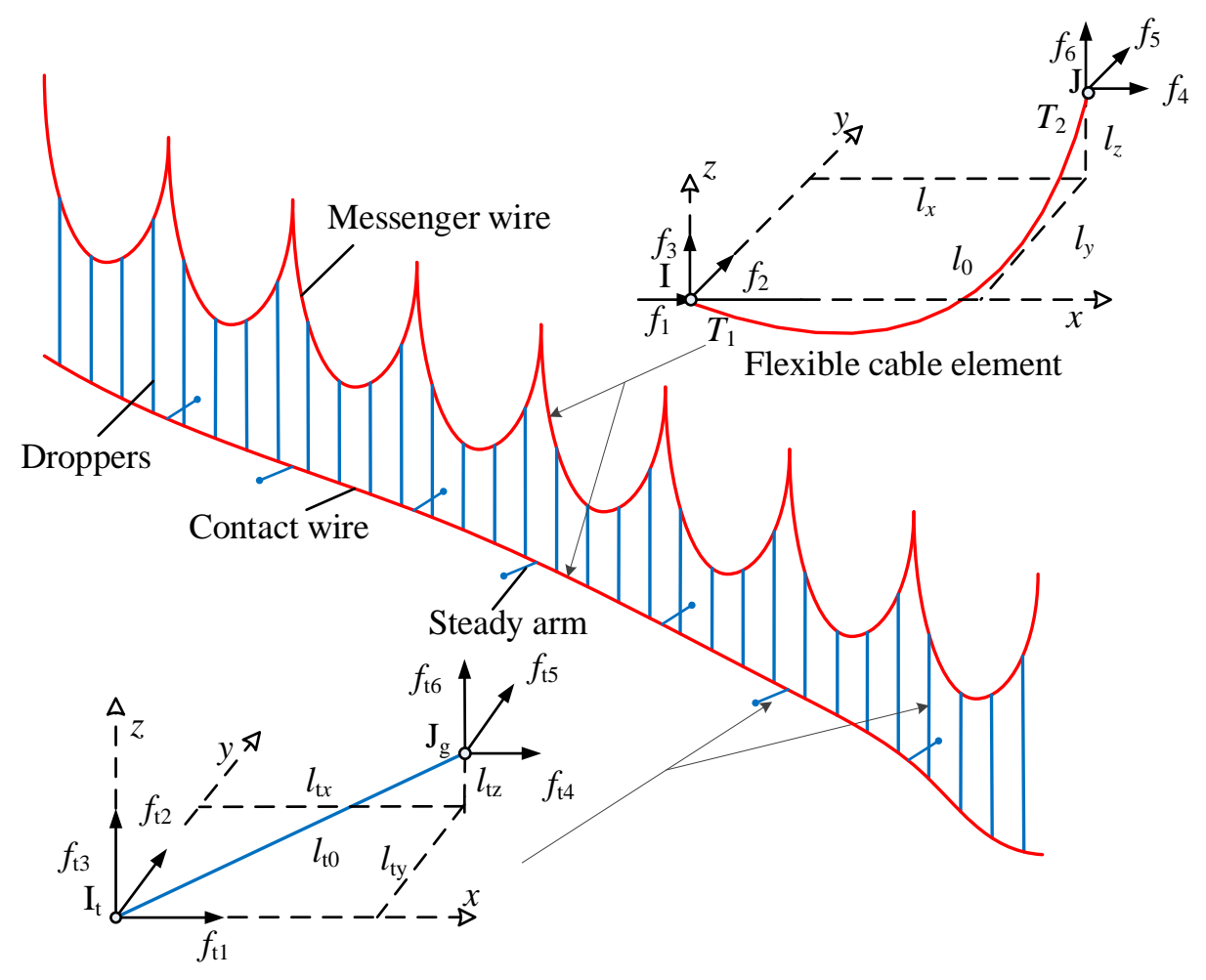

Figure 7. Catenary model with cable and truss elements

\subsubsection{Flexible Cable Element}

Consider a cable element with two nodes, as presented in Figure 7. The relative distances between the two nodes can be expressed by the nodal forces as [50]:

$$
\begin{aligned}
& l_{\mathrm{x}}=-\left(f_{1} l_{0}\right) /(E A)-f_{1}\left\{\ln \left(\sqrt{f_{4}^{2}+f_{5}^{2}+f_{6}^{2}}+f_{6}\right)-\right. \\
&\left.\ln \left(\sqrt{f_{1}^{2}+f_{2}^{2}+f_{3}^{2}}-f_{3}\right)\right\} / w \\
& l_{\mathrm{y}}=-f_{2} l_{0} /(E A)+f_{2}\left\{\operatorname { l n } \left[\sqrt{f_{1}^{2}+f_{2}^{2}+\left(w l_{0}-f_{3}\right)^{2}}\right.\right. \\
&+\left.\left.w l_{0}-f_{3}\right]-\ln \left(\sqrt{f_{1}^{2}+f_{2}^{2}+f_{3}^{2}}-f_{3}\right)\right\} / w
\end{aligned}
$$




$$
\begin{aligned}
& l_{\mathrm{z}}=-\left(f_{3} l_{0}\right) /(E A)+\left(w l_{0}^{2}\right) /(2 E A)+ \\
& {\left[\sqrt{f_{4}^{2}+f_{5}^{2}+f_{6}^{2}}-\sqrt{f_{1}^{2}+f_{2}^{2}+f_{3}^{2}}\right] / w}
\end{aligned}
$$

in which, $l_{\mathrm{x}}, l_{\mathrm{y}}$, and $l_{\mathrm{z}}$ are the relative distances along the local $x, y$ and $z$ axes, respectively, $w$ is the self-weight and $l_{0}$ is the undeformed length, $E$ is the Young's modulus, $A$ is the cross-sectional area, and $f_{1} \sim f_{3}$ and $f_{4} \sim f_{6}$ are the nodal forces at node I and $\mathrm{J}$. The force equilibrium of the cable element can be expressed by:

$$
f_{1}+f_{4}=0 \quad f_{5}+f_{2}=0 \quad f_{6}+f_{3}=w l_{0}
$$

If $l_{\mathrm{x}}, l_{\mathrm{y}}$, and $l_{\mathrm{z}}$ are given, $f_{1} \sim f_{6}$ can be obtained by solving Eq. (1-2) through the Newton-Raphson method. Substituting Eq. (2) into Eq. (1), partial differentiation of both sides of Eq. (1) yields the following incremental relationships between the relative nodal distances and nodal forces.

$$
\left\{\begin{array}{l}
\Delta l_{\mathrm{x}} \\
\Delta l_{\mathrm{y}} \\
\Delta l_{\mathrm{z}}
\end{array}\right\}=\left[\begin{array}{lll}
\frac{\partial l_{\mathrm{x}}}{\partial f_{1}} & \frac{\partial l_{\mathrm{x}}}{\partial f_{2}} & \frac{\partial l_{\mathrm{x}}}{\partial f_{3}} \\
\frac{\partial l_{\mathrm{y}}}{\partial f_{1}} & \frac{\partial l_{\mathrm{y}}}{\partial f_{2}} & \frac{\partial l_{\mathrm{y}}}{\partial f_{3}} \\
\frac{\partial l_{\mathrm{z}}}{\partial f_{1}} & \frac{\partial l_{\mathrm{z}}}{\partial f_{2}} & \frac{\partial l_{\mathrm{z}}}{\partial f_{3}}
\end{array}\right]\left\{\begin{array}{c}
\Delta f_{1} \\
\Delta f_{2} \\
\Delta f_{3}
\end{array}\right\}+\left[\begin{array}{c}
\frac{\partial l_{\mathrm{x}}}{\partial l_{0}} \\
\frac{\partial l_{\mathrm{y}}}{\partial l_{0}} \\
\frac{\partial l_{\mathrm{z}}}{\partial l_{0}}
\end{array}\right] \Delta l_{0}
$$

Taking the inverse of the flexibility matrix in Eq. (3), yields the incremental equation of the cable element.

$$
\Delta \mathbf{F}_{\mathrm{C}}=\mathbf{K}_{\mathbf{C}} \Delta \mathbf{U}_{\mathrm{C}}+\mathbf{K}_{\mathrm{CL}} \Delta l_{0}
$$

in which, $\Delta \mathbf{F}_{\mathbf{C}}$ is the incremental nodal force vector, $\mathbf{K}_{\mathbf{C}}$ is the stiffness matrix related to the nodal displacements, $\Delta \mathbf{U}_{\mathbf{C}}$ is the incremental displacement vector and $\mathbf{K}_{\mathrm{CL}}$ is the 3 by 1 stiffness matrix related to the undeformed length of the cable.

The tension is applied on the endpoint of the messenger/contact wire. Considering a cable element with a constant tension $T_{0}$, an additional constraint condition is given as:

$$
T_{0}=\sqrt{f_{1}^{2}+f_{2}^{2}+f_{3}^{2}}
$$

\subsubsection{Truss Element}

The equilibrium equation of the truss element, represented in Figure 7, is written as [51]: 


$$
\begin{aligned}
& f_{\mathrm{t} 1}=-E_{\mathrm{t}} A_{\mathrm{t}}\left(\frac{l_{\mathrm{tx}}}{l_{t 0}}-\frac{l_{\mathrm{tx}}}{\sqrt{l_{\mathrm{tx}}^{2}+l_{\mathrm{ty}}^{2}+l_{\mathrm{tz}}^{2}}}\right) \\
& f_{\mathrm{t} 2}=-E_{\mathrm{t}} A_{\mathrm{t}}\left(\frac{l_{\mathrm{ty}}}{l_{t 0}}-\frac{l_{\mathrm{ty}}}{\sqrt{l_{\mathrm{tx}}^{2}+l_{\mathrm{ty}}^{2}+l_{\mathrm{tz}}^{2}}}\right) \\
& f_{\mathrm{t} 3}=-E_{\mathrm{t}} A_{\mathrm{t}}\left(\frac{l_{\mathrm{tz}}}{l_{\mathrm{t} 0}}-\frac{l_{\mathrm{tz}}}{\sqrt{l_{\mathrm{tx}}^{2}+l_{\mathrm{ty}}^{2}+l_{\mathrm{tz}}^{2}}}\right)
\end{aligned}
$$

in which $f_{\mathrm{t} 1} \sim f_{\mathrm{t} 3}$ are the nodal forces at node $\mathrm{I}_{\mathrm{t}}, l_{\mathrm{tx}}, l_{\mathrm{ty}}$ and $l_{\mathrm{tz}}$ are the relative distances between two nodes along the local $x_{\mathrm{t}}, y_{\mathrm{t}}$ and $z_{\mathrm{t}}$ axes, $l_{\mathrm{t} 0}$ is the undeformed length, $E_{\mathrm{t}}$ is the Young's modulus and $A_{\mathrm{t}}$ is the cross-sectional area. Considering a nonlinear dropper behaviour, $E_{\mathrm{t}} A_{\mathrm{t}}$ changes to zero when the dropper works in compression. The stiffness matrix of the truss element can be obtained through differentiating both sides of Eq. (6) as follows.

$$
\Delta \mathbf{F}_{\mathbf{T}}=\mathbf{K}_{\mathbf{T}} \Delta \mathbf{U}_{\mathbf{T}}+\mathbf{K}_{\mathbf{T L}} \Delta l_{\mathrm{t} 0}
$$

where $\Delta \mathbf{F}_{\mathrm{T}}$ is the incremental nodal force vector, $\mathbf{K}_{\mathrm{T}}$ is the stiffness matrix related to the nodal displacements, $\Delta \mathbf{U}_{\mathbf{T}}$ is the incremental displacement vector and $\mathbf{K}_{\mathbf{T L}}$ is the stiffness matrix related to the undeformed length of the truss.

It should be noted that the terms related to $\Delta l_{0}$ and $\Delta l_{\mathrm{t} 0}$ in Eqs. (4) and (7) are used in the TCUD method to calculate the initial shape of the catenary. To solve the catenary equations of motion, built from the assemblage of all the cable and truss elements evaluated in each time step, the Newmark integration method is used. To account for the dropper slacking and the geometrical nonlinearity of the messenger/contact wire, the assembled equations are re-evaluated in each time step within a Newton-Raphson iteration procedure that assures the solution convergence. To couple the pantograph and catenary, the penalty function method is adopted to calculate the contact force using the penetration of the contact surfaces. To reduce the CPU time in the simulations, a moving mesh approach is implemented in each time step to re-mesh the contact wire according to the position of the contact point [52].

\subsection{TCUD Method}

The principle of the TCUD method proposed by Kim and Lee [53] is to set the undeformed length as unknown parameters, as seen in Eqs. (4) and (7), and formulate the stiffness matrix with nodal forces and undeformed length for each element. In this manner, more constraint conditions are required to eliminate the undesirable 
deformations of the catenary. Assembling Eqs. (4) and (7), the global incremental equilibrium equation for the catenary is obtained as:

$$
\Delta F=K_{G} \Delta U+K_{L} \Delta L=\left[\begin{array}{ll}
K_{G} & K_{L}
\end{array}\right]\left[\begin{array}{l}
\Delta U \\
\Delta L
\end{array}\right]
$$

where $\Delta \mathbf{F}$ is the unbalanced force vector, $\mathbf{K}_{\mathbf{G}}$ and $\mathbf{K}_{\mathbf{L}}$ are the global stiffness matrices related to the incremental nodal displacement vector $\Delta \mathbf{L}$ and the incremental undeformed length vector $\Delta \mathbf{U}$, respectively. Assume that the total number of degrees of freedom is $n$, and that the number of elements is $m$. So, $\left[\begin{array}{ll}\mathbf{K}_{\mathbf{G}} & \mathbf{K}_{\mathbf{L}}\end{array}\right]$ is a $n \times(m+n)$ matrix. Since the total number of unknowns $(m+n)$ in Eq. (8) exceeds the total number of equations $n$, Eq. (8) has infinite solutions. Hence, additional constraint conditions are required to control the solution of Eq. (8). They are set according to the design specification and the static measurement data. In this article, the following additional constraint conditions are defined:

- The vertical position of dropper point in the contact wire is restricted according to the reserved pre-sag and the contact wire irregularities;

- The longitudinal direction of each node is restricted to suppress the longitudinal movement;

- The Eq. (5) is applied to the endpoints of messenger and contact wires to impose traction in the two wires.

These constraint conditions supply the additional $m$ equations that reduce the numbers of unknowns in Eq. (8). The equality between the numbers of equations and unknowns ensures a unique solution for the target configuration of the catenary. Finally, the nodal coordinates and undeformed lengths can be determined by solving Eq. (8) iteratively.

\subsection{Shape-Finding of Catenary with Contact Wire Irregularities}

In order to build the catenary model with measured irregularities, such as the one presented in Figure 2, a three-step procedure is used where the TCUD is of fundamental importance to initialise the catenary model. The parameters of the catenary are detailed in Table 1, according to its design specification. The three steps to calculate the exact configuration are described as follows.

Table 1. General properties of catenary

\begin{tabular}{ll}
\hline \hline Catenary Type & Simple \\
Contact Wire / Tension & RiM $120 / 27 \mathrm{kN}$ \\
Messenger Wire / Tension & Bz II $120 / 21 \mathrm{kN}$ \\
Stitch Wire / Tension / Length & None \\
Dropper & Bz II 10 \\
Dropper Spacing at Support / Field & $2 \mathrm{~m}-5 \mathrm{~m} / \max .10 \mathrm{~m}$ \\
Span Length & $42 \mathrm{~m}-55 \mathrm{~m}$ \\
Encumbrance & $1.6 \mathrm{~m}$ \\
\hline
\end{tabular}




\begin{tabular}{ll}
\hline Stagger & $\pm 0.3 \mathrm{~m}$ \\
Contact Wire Height & $5.3 \mathrm{~m}$ \\
Steady Arm Length / Mass & $1.2 \mathrm{~m} / 0.85 \mathrm{~kg}$ \\
\hline \hline
\end{tabular}

In Step 1, the measured irregularly data is pre-processed such that a filter is applied within the spatial frequency range from 0 to $0.13 \mathrm{~m}^{-1}$. This is to eliminate measurement errors, as presented in Figure 8 in comparison with Figure 5.

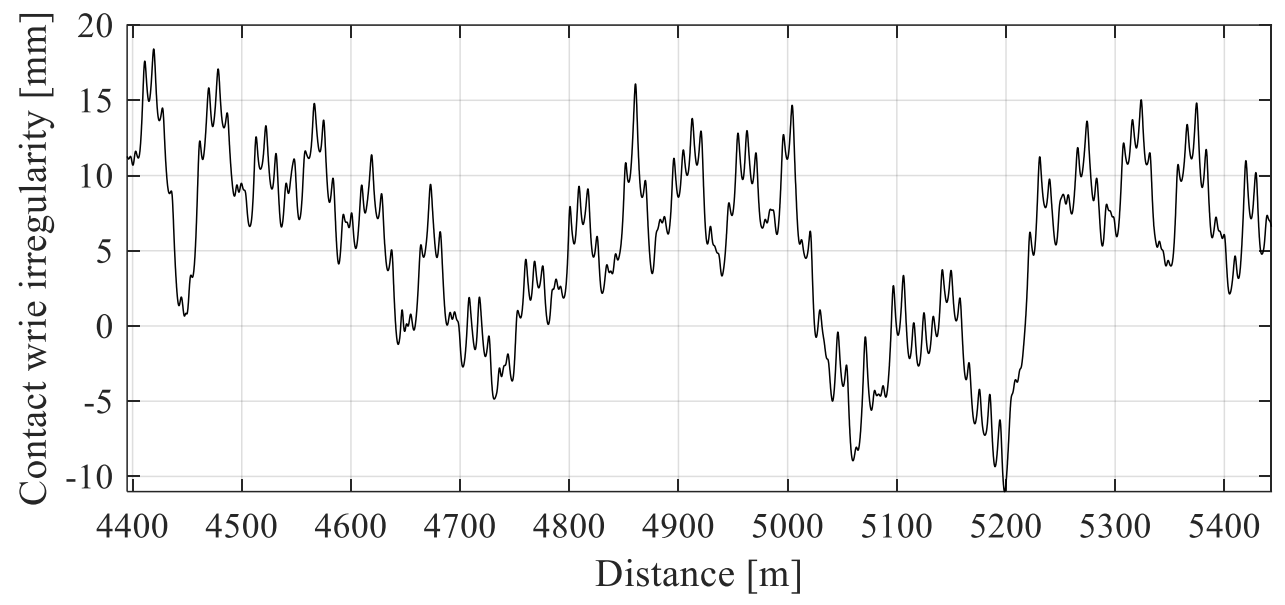

Figure 8. Filtered data of contact wire irregularities

The second step consists of determining the dropper and steady arm positions at the contact wire. Here its corresponding vertical irregularly is extracted from the filtered data and added to its nominal position. Figure 9 presents the vertical irregularities found at each of these key points.

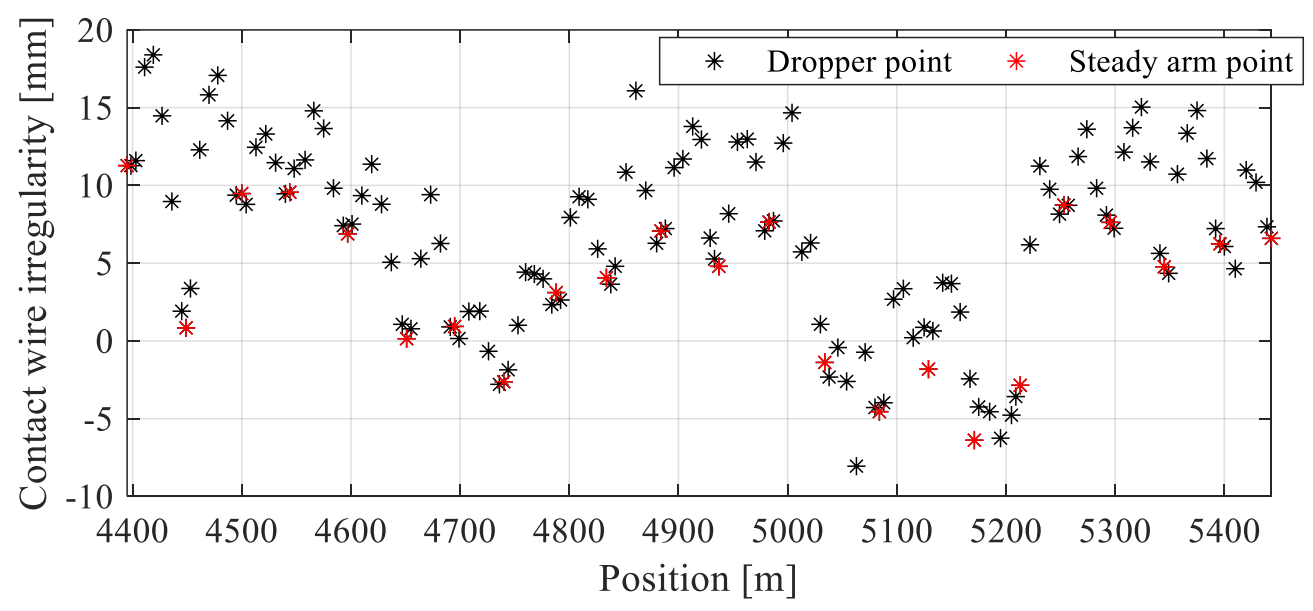

Figure 9. Extracted dropper and steady arm points

Step 3 concerns the catenary shape-finding procedure where the established key point positions are taken as the constraint conditions to compute the catenary configuration by TCUD method described in Section 3.2. 
The resulting contact wire height is shown in Figure 10 (a). In comparison with Figure 8, it can be noticed that a good consistency with the measurement data is achieved. The difference between the nominal contact wire height along the track and the actual height when considering irregularities can also be observed. Figure 10 (b) presents the full geometry of the catenary with the superposition of the two effects. This model is used in the following dynamic simulations, and the analysis range is chosen from $350 \mathrm{~m}$ to $1148 \mathrm{~m}$.

(a)

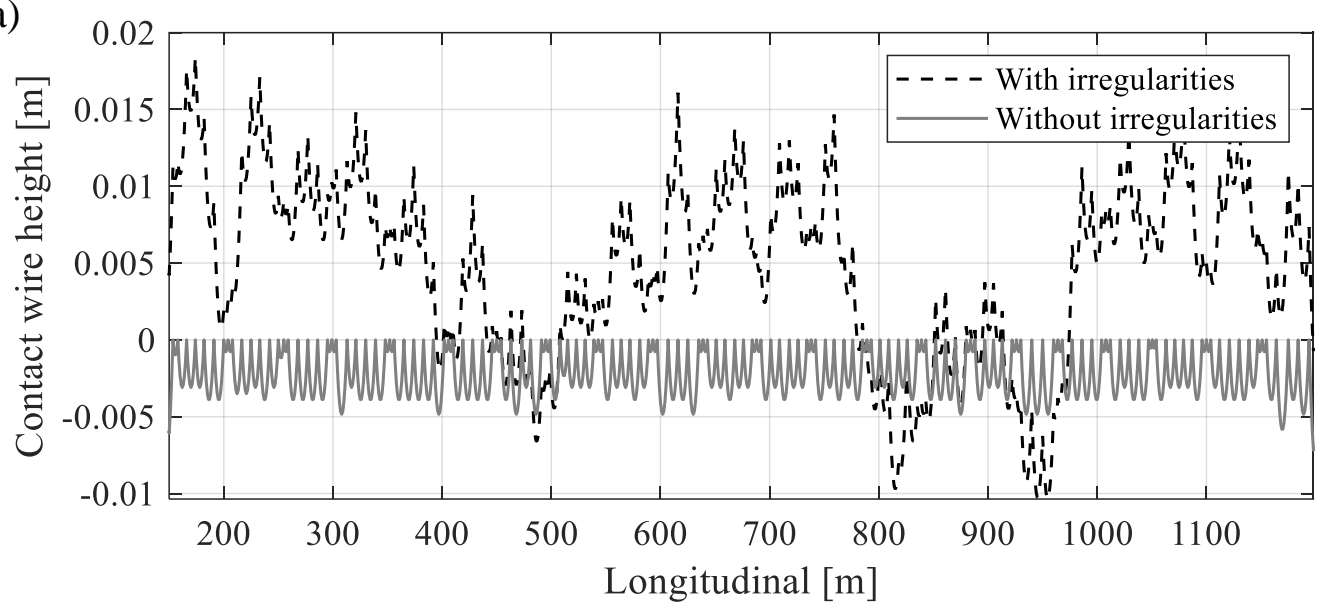

(b)

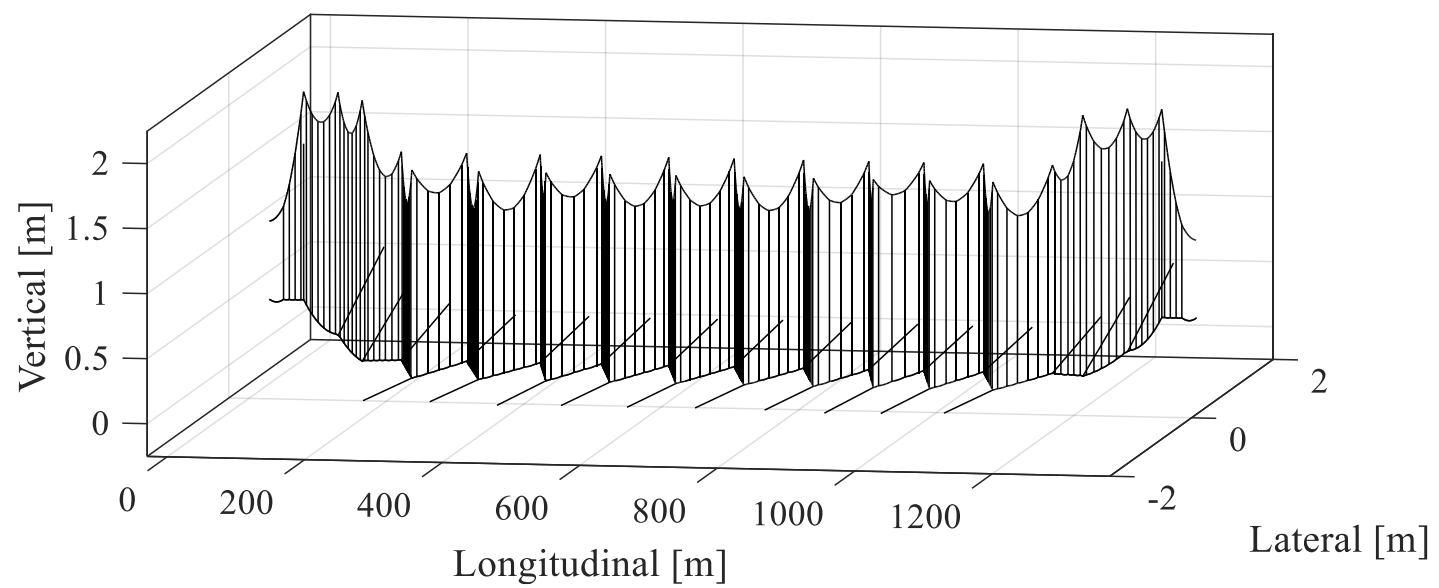

Figure 10. Results of catenary geometry: (a) Contact wire height; (b) Full geometry

\section{Effect of contact wire irregularities on pantograph-catenary interaction}

The Faiveley CX pantograph is widely used in the Chinese railway network. Its lumped mass model representation, as presented in Figure 11 and in Table 2, is adopted here to study the interaction with the catenary. The aerodynamic forces acting on the pantograph are assumed as two vertical forces applied on both masses. They are evaluated by the products of the train speed and the aerodynamic coefficients $k_{\mathrm{p} 1}$ and $k_{\mathrm{p} 2}$. The interaction between the pantograph collector and the contact wire is realised using a penalty formulation.

To understand the effect of contact wire irregularities on the pantograph-catenary dynamic performance, a set of simulations are run considering catenary models with and without irregularities. In addition, different train speeds are considered, starting from 
$300 \mathrm{~km} / \mathrm{h}$, which is the nominal operational speed of the Chinese high-speed network. The contact force results are also compared with the previous method, which takes the irregularities as additional rigid displacement on the contact wire.

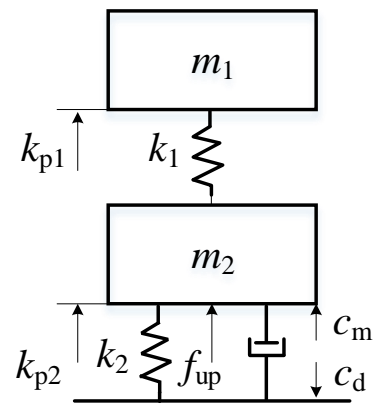

Figure 11. Lumped mass model of the Faiveley CX pantograph

Table 2. Parameters of Faiveley CX pantograph

\begin{tabular}{|c|c|c|c|c|}
\hline$m_{1}[\mathrm{~kg}]$ & $m_{2}[\mathrm{~kg}]$ & $k_{1}[\mathrm{~N} / \mathrm{m}]$ & $k_{2}[\mathrm{~N} / \mathrm{m}]$ & $f_{\text {up }}[\mathrm{N}]$ \\
\hline 5 & 18.98 & 6000 & 0.5 & 70 \\
\hline$c_{\mathrm{m}}[\mathrm{N} \mathrm{s} / \mathrm{m}]$ & $c_{\mathrm{d}}[\mathrm{N} \mathrm{s} / \mathrm{m}]$ & $k_{\mathrm{p} 1}\left[\mathrm{~N} \mathrm{~s}^{2} / \mathrm{m} 2\right]$ & $k_{\mathrm{p} 2}\left[\mathrm{~N} \mathrm{~s}^{2} / \mathrm{m}^{2}\right]$ & \\
\hline 5 & 350 & 0.006 & 0.006 & \\
\hline
\end{tabular}

\subsection{Analysis with Normal Speed}

The pantograph-catenary interaction results at $300 \mathrm{~km} / \mathrm{h}$ are presented in Figure 12. It is noticeable the increase of the contact force amplitude caused by the presence of contact wire irregularities. Local peaks also increase significantly when catenary irregularities are present.

To facilitate the analysis of the range and the distribution characteristics of contact forces, the boxplots of the contact force are presented in Figure 13 (a). The boxplot is a standardized way to display the distribution of data based on a summary of five numbers, which are the minimal value $Q_{\min }$, the first quartile $Q_{1}$, the median $Q_{2}$, the third quartile $Q_{3}$, and the maximal value $Q_{\max }$. Usually the maximal and minimal can be calculated by the following two equations respectively.

$$
\begin{aligned}
& Q_{\text {max }}=Q_{3}+1.5 \times I Q R \\
& Q_{\text {min }}=Q_{1}-1.5 \times I Q R
\end{aligned}
$$

in which, IQR is the range from the $25^{\text {th }}$ to $75^{\text {th }}$ percentile. Without the contact wire irregularity, the boxplot of contact forces depicted in Figure 13 (a) is nearly symmetric 
with respect to the median value $Q_{2}$, which means that the contact force approximately obeys normal distribution. When the contact wire irregularity is presented, the range of contact forces increases, and the contact force data presents higher dispersion. The normal distribution of the contact forces is skewed by the contact wire irregularities.

Some statistic parameters, namely statistical maximum and minimum, standard deviation and mean value, of the contact forces are depicted in Figure 13 (b). It is observed that the presence of the contact wire irregularities does not change the mean contact force but increases the standard deviation by $3.74 \%$, which causes the increase of the statistical maximum and the decrease of the statistical minimum.

Through the spectral estimation of the contact force, the PSD of the contact force versus spatial frequency is presented in Figure 14. It can be observed that the contact wire irregularities cause a significant increase of PSD peaks at the spatial frequencies related to the span length and dropper spacing. These are consistent with the dominant frequencies of the contact wire irregularity shown in Figure 6.

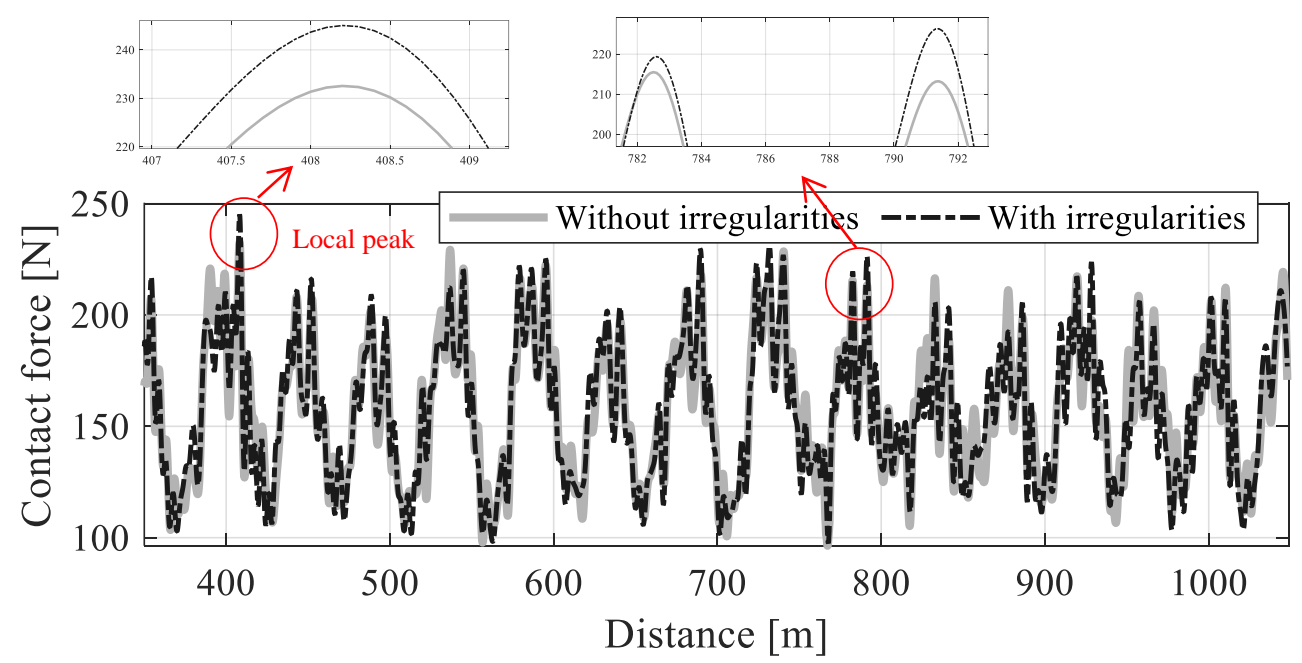

Figure 12. Contact forces at $300 \mathrm{~km} / \mathrm{h}$

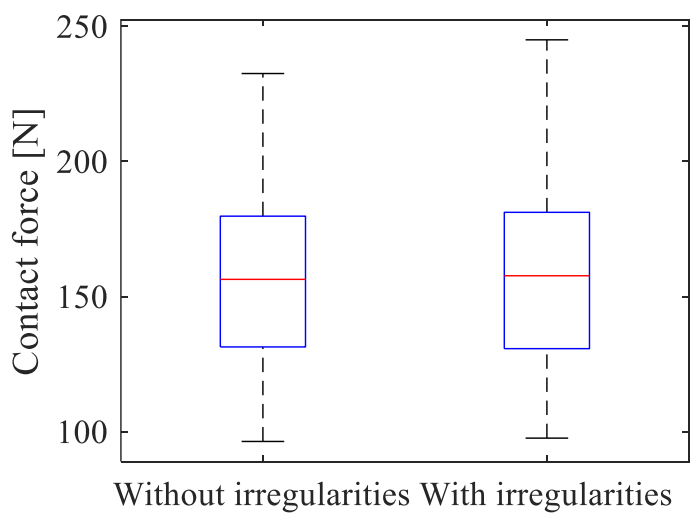

(a)

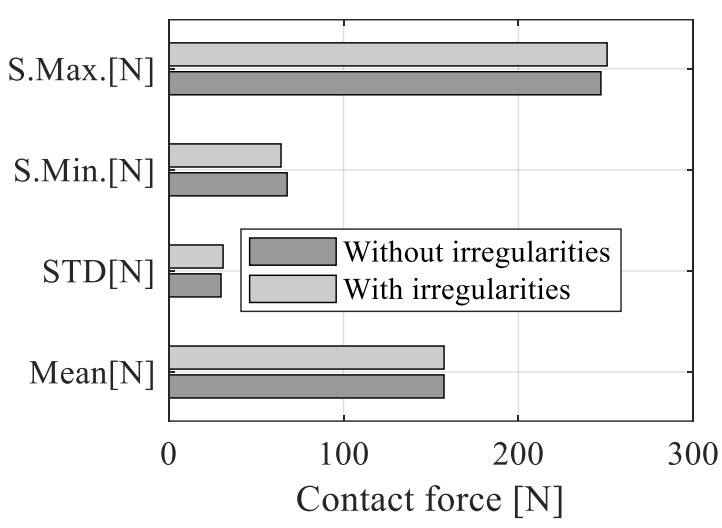

(b)

Figure 13. Statistics of contact force at $300 \mathrm{~km} / \mathrm{h}$ : (a) box plots; (b) statistical values 


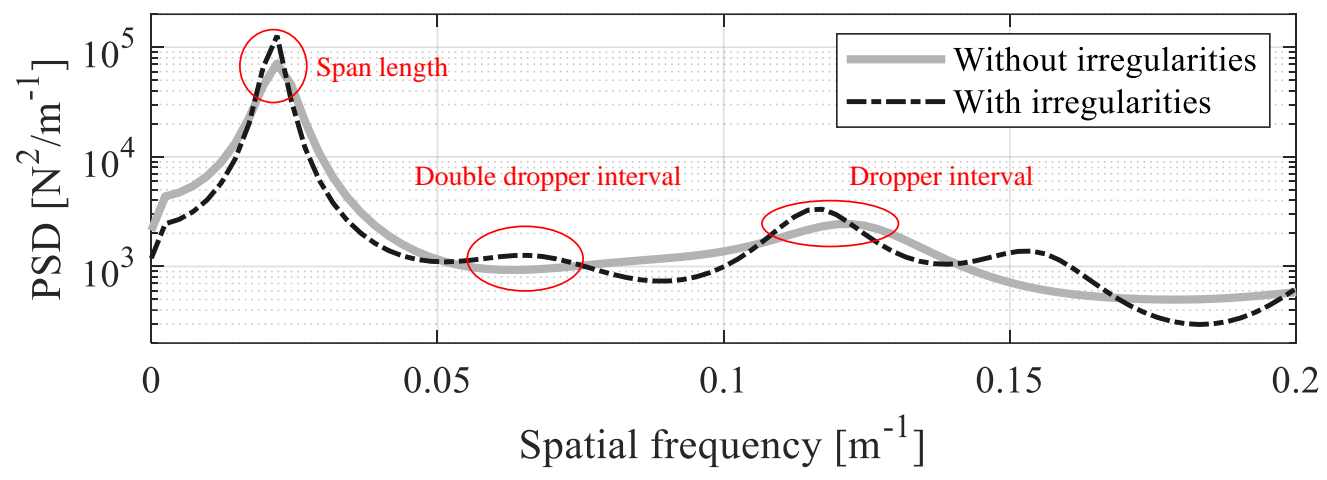

Figure 14. PSD of contact forces at $300 \mathrm{~km} / \mathrm{h}$

\subsection{Effect of Contact Wire Irregularities with Speed Upgrade}

In order to understand the effect of catenary irregularities at higher speeds, 300 to 380 $\mathrm{km} / \mathrm{h}$, a summary of the evaluated contact force standard deviation and mean values are presented in Figure 15 and Figure 16, respectively. At each speed, the mean contact force is tuned to follow the formula of the mean contact force dependent on the train speed defined in EN 50367 [54]. When the catenary irregularities are presented, the standard deviation always increases. Particularly, at $340 \mathrm{~km} / \mathrm{h}$ the presence of the contact wire irregularities causes the increase of the contact force standard deviation by $9.64 \%$. The evaluated contact forces along the track at $320 \mathrm{~km} / \mathrm{h}, 340 \mathrm{~km} / \mathrm{h}, 360 \mathrm{~km} / \mathrm{h}$ and $380 \mathrm{~km} / \mathrm{h}$ are presented in Figure 17 (a-d), respectively. In general, the contact force amplitude is increased by the presence of the contact wire irregularity at each speed, which is manifested by the increase of local peaks. The boxplots of the evaluated contact forces at $320 \mathrm{~km} / \mathrm{h}, 340 \mathrm{~km} / \mathrm{h}, 360 \mathrm{~km} / \mathrm{h}$ and $380 \mathrm{~km} / \mathrm{h}$ are presented in Figure $18(\mathrm{a}-\mathrm{d})$, respectively. At each speed, when the contact wire irregularities are presented, the range of contact forces significantly increases and the contact force data presents higher dispersion. In general, the presence of the catenary irregularities disrupts the symmetry of the boxplot with respect to the median value and skews the normal distribution of the contact forces.

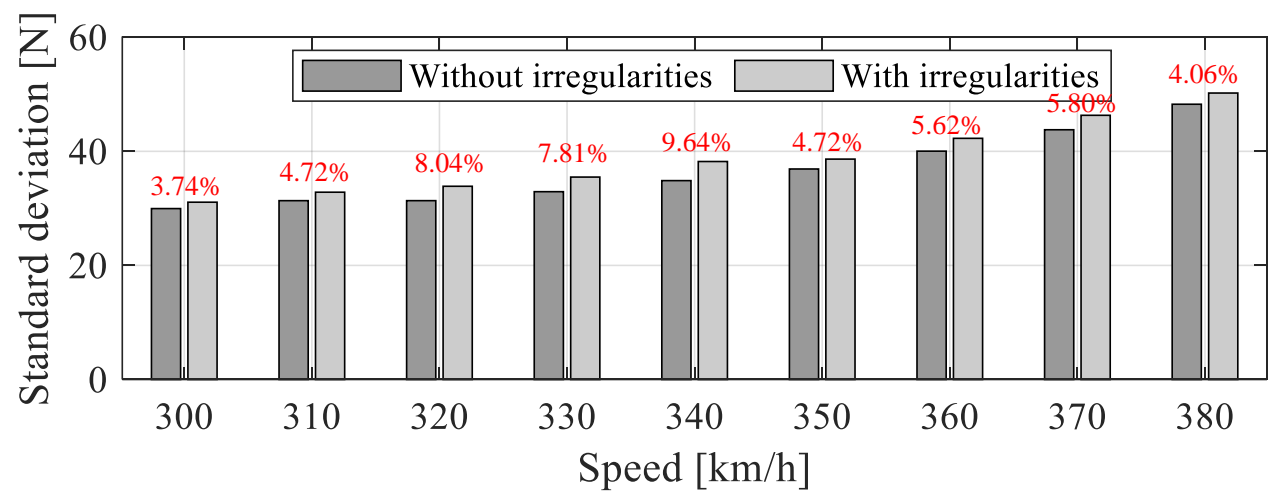

Figure 15. Contact force standard deviation at different speeds 


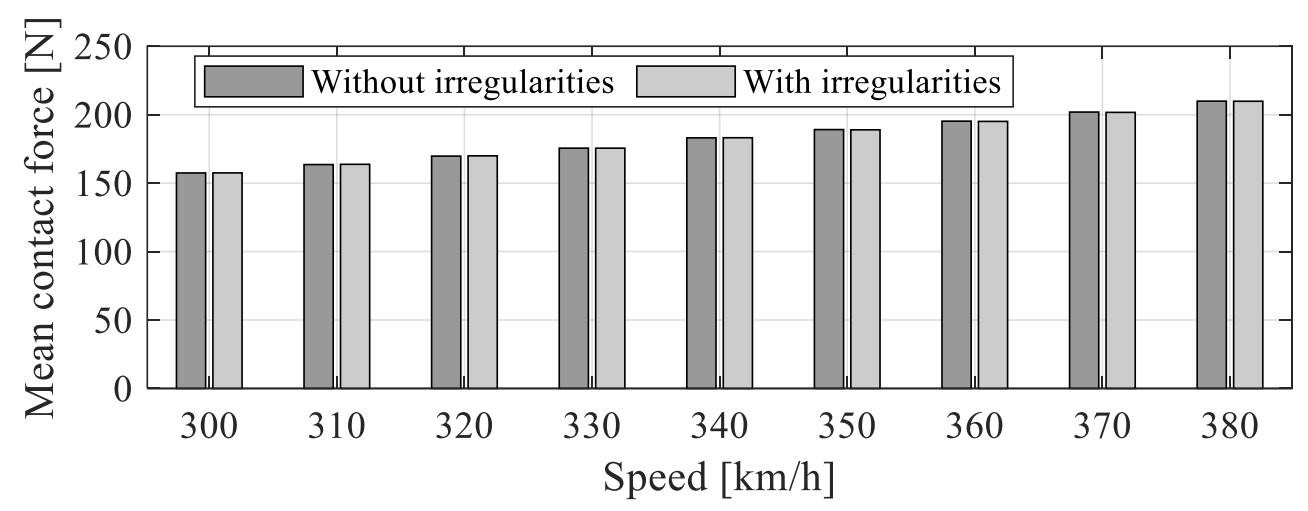

Figure 16. Mean contact force at different speeds

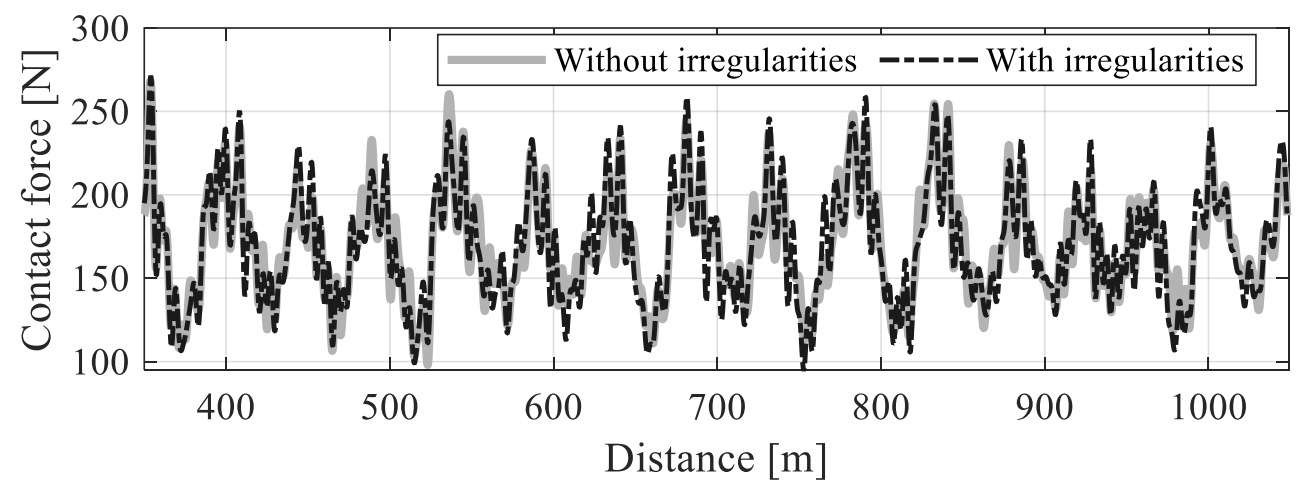

(a)

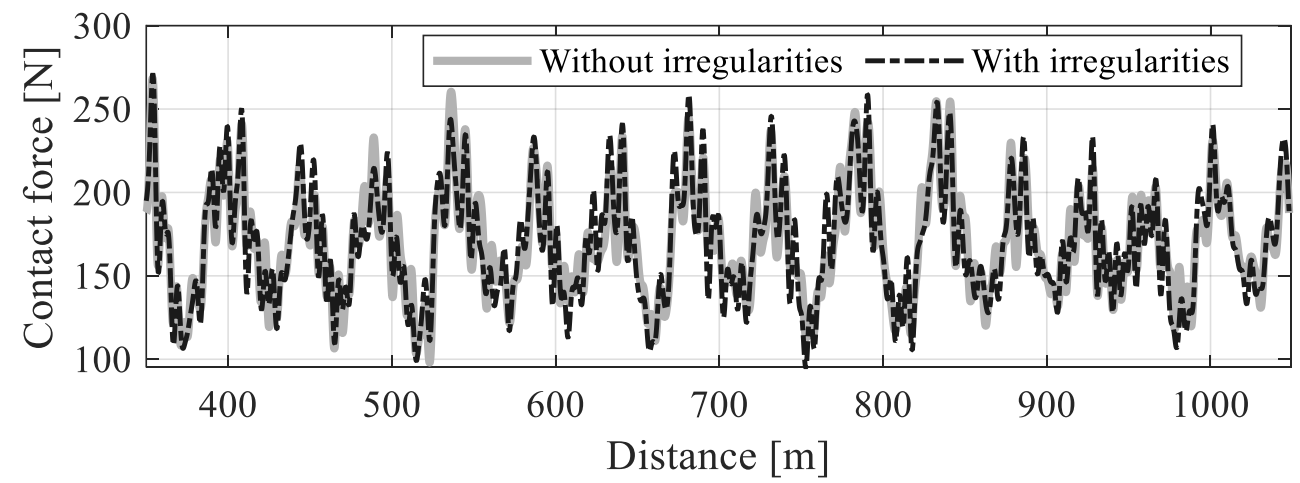

(b)

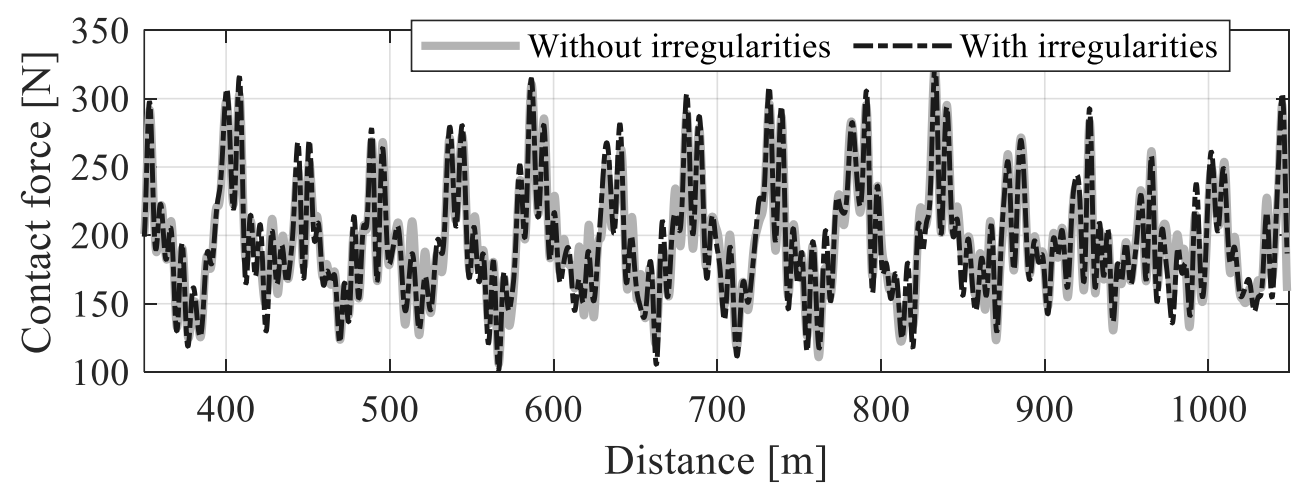

(c) 


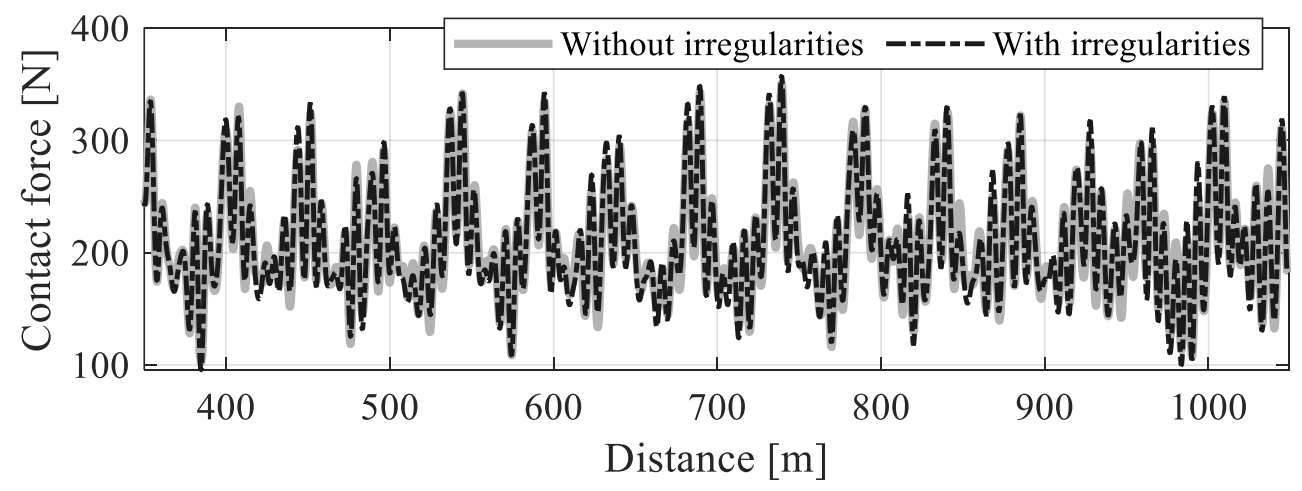

(d)

Figure 17. Contact forces at (a) $320 \mathrm{~km} / \mathrm{h}$; (b) $340 \mathrm{~km} / \mathrm{h}$; (c) $360 \mathrm{~km} / \mathrm{h}$ and (d) $380 \mathrm{~km} / \mathrm{h}$

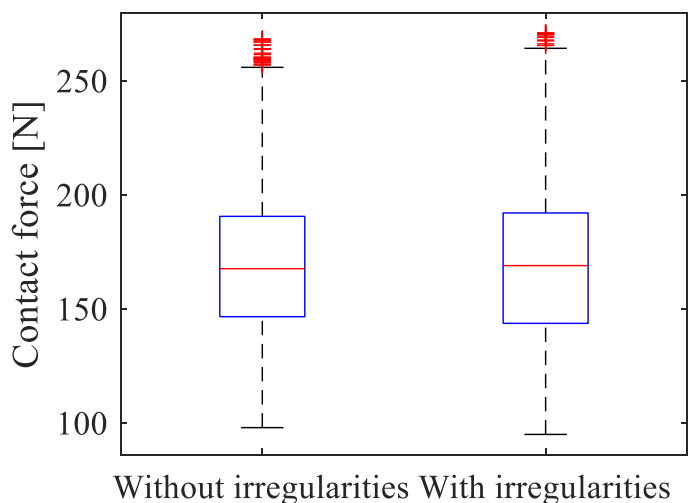

(a)

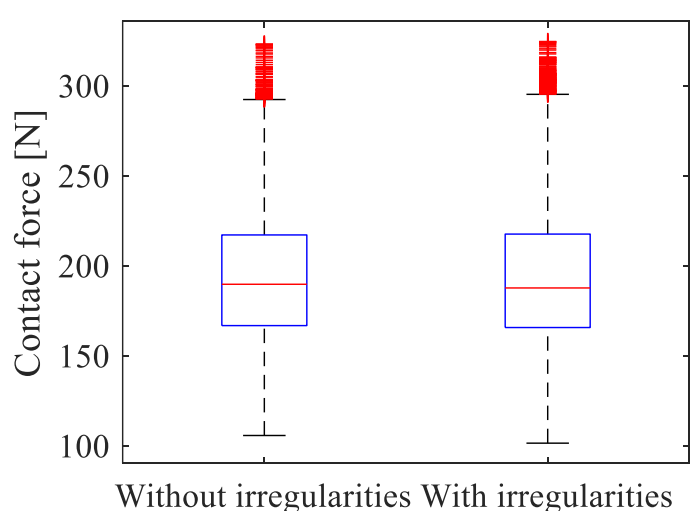

(c)

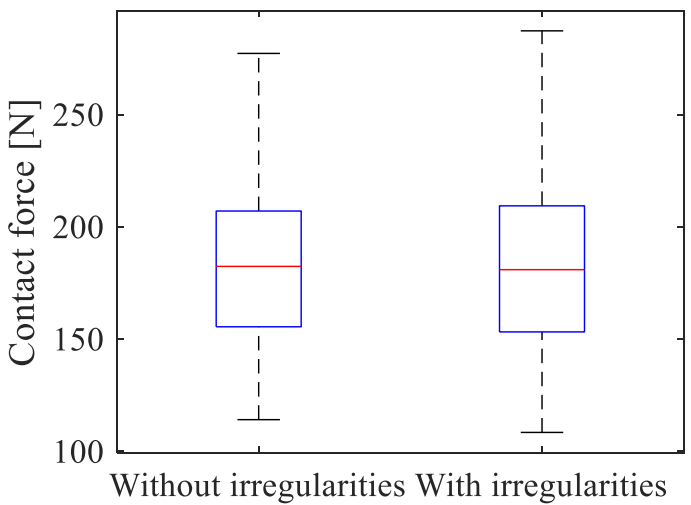

(b)

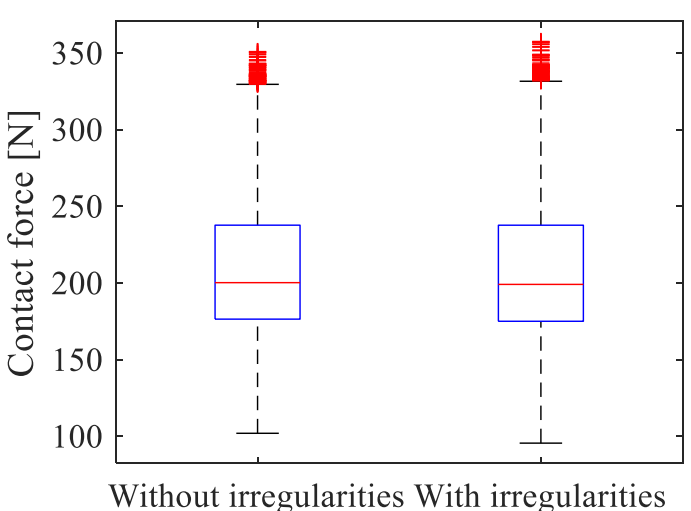

(d)

Figure 18. Boxplots of contact forces at (a) $320 \mathrm{~km} / \mathrm{h}$; (b) $340 \mathrm{~km} / \mathrm{h}$; (c) $360 \mathrm{~km} / \mathrm{h}$ and (d) $380 \mathrm{~km} / \mathrm{h}$

In order to see the effect of contact wire irregularities on the operational safety of the catenary, the maximum contact forces are presented in Figure 19. It is observed that the catenary irregularities cause an increment in the maximum contact force at each speed. Particularly, at the speeds of $300 \mathrm{~km} / \mathrm{h}$ and $340 \mathrm{~km} / \mathrm{h}$, the contact wire irregularity causes the increase of the maximum contact force above $10 \mathrm{~N}$. The maximum allowed contact force for the catenary is $350 \mathrm{~N}$. It is noticeable that the maximum contact force is out of 
the safety limits at $380 \mathrm{~km} / \mathrm{h}$, which is very close to the critical speed of the catenary here considered $378.3 \mathrm{~km} / \mathrm{h}$, i.e., $70 \%$ of the catenary wave propagation speed. It is, therefore, evident that the contact wire irregularities have a negative effect on the pantographcatenary dynamics, inducing more damage on the components of both systems.

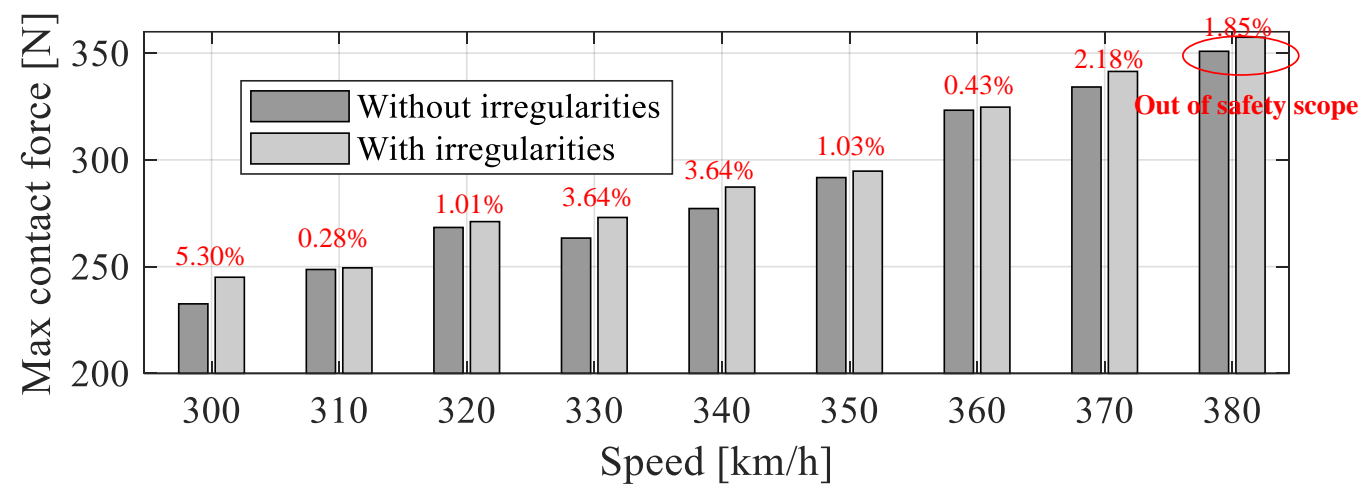

Figure 19. Maximum contact forces at different speeds

\subsection{Comparison with Previous Method}

In previous studies $[41,44,45]$, the contact wire irregularities are normally treated as additional rigid displacements to calculate the contact force. Using the penalty function method, the contact force $f_{\mathrm{c}}$ can be evaluated by:

$$
f_{\mathrm{c}}=\left\{\begin{array}{ccc}
K_{\mathrm{s}}\left(z_{\mathrm{p}}-z_{\mathrm{c}}-z_{\mathrm{r}}\right) & \text { if } & z_{\mathrm{p}} \geq z_{\mathrm{c}}+z_{\mathrm{r}} \\
0 & \text { if } & z_{\mathrm{p}}<z_{\mathrm{c}}+z_{\mathrm{r}}
\end{array}\right.
$$

where $K_{\mathrm{s}}$ is the contact stiffness, $z_{\mathrm{p}}$ is the uplift of pantograph head, $z_{\mathrm{c}}$ is the contact wire uplift at the contact point, and $z_{\mathrm{r}}$ is the additional rigid displacement caused by the contact wire irregularity. In the present method, $z_{\mathrm{r}}$ vanishes in the equation as the contact wire irregularities have been added in the initialisation of the catenary. In order to understand the difference between the previous method and the present methodology, the contact force results calculated by the two methods, at different speeds, are compared. The comparison of the contact force standard deviations and mean values are presented in Figure 20 and Figure 21, respectively. At each speed, the mean contact force is tuned to follow the formula of the mean contact force as function on the train speed defined in EN 50367 [54]. Generally, the contact force standard deviation obtained by the previous method is higher than the values obtained with the formulation proposed here. Particularly at $300 \mathrm{~km} / \mathrm{h}$, the difference in percentage between the two methods reaches $9.07 \%$. Figure 22 presents the contact forces distribution at $300 \mathrm{~km} / \mathrm{h}$ and $350 \mathrm{~km} / \mathrm{h}$. It is observed that the interaction forces calculated by the two methods have similar patterns at each speed, but the previous method causes the bigger amplitude of the contact forces. The previous method treats the contact wire irregularities as a series of hard spots on the contact wire, which overestimates the negative effect of contact wire irregularities. 


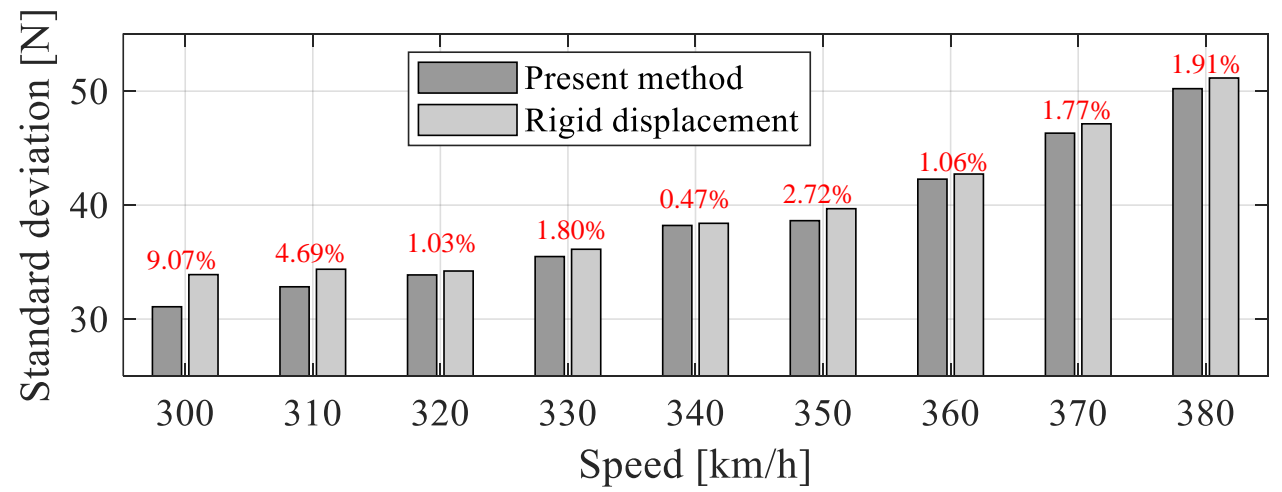

Figure 20. Comparison of contact force standard deviations calculated by two methods

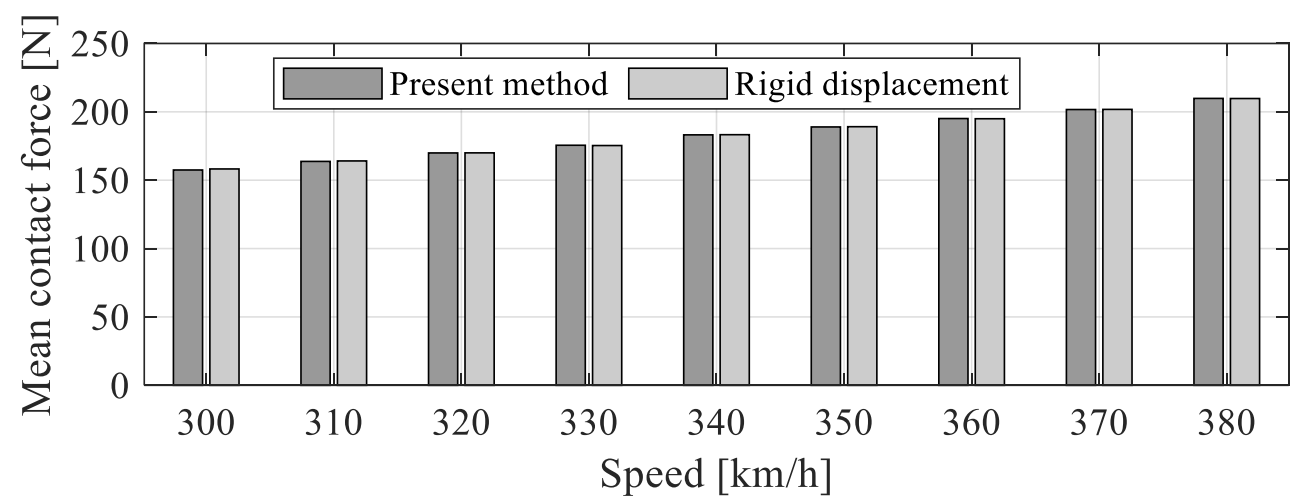

Figure 21. Comparison of mean contact forces calculated by two methods

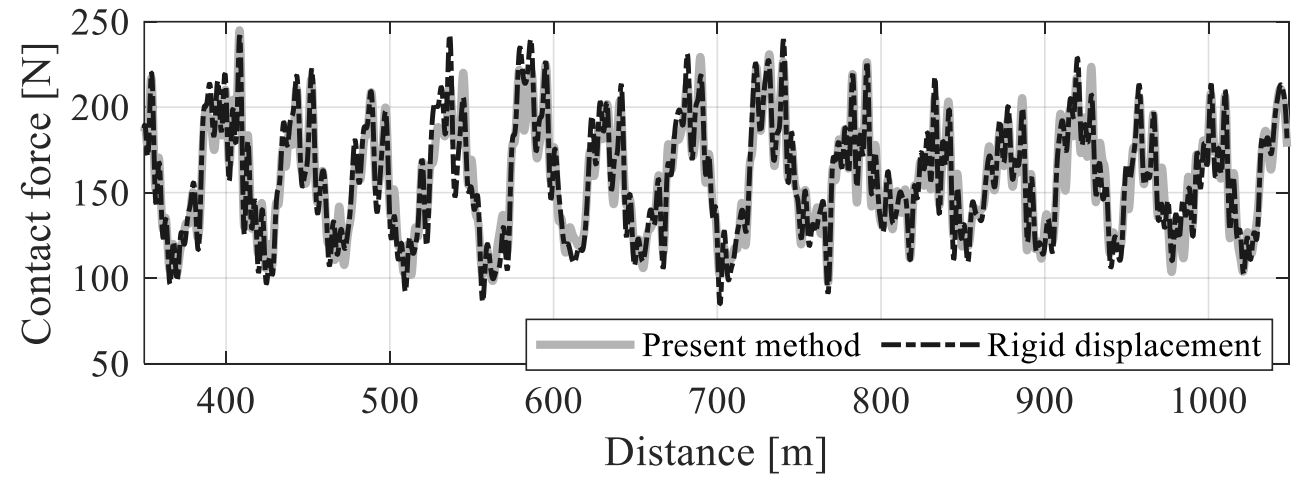

(a)

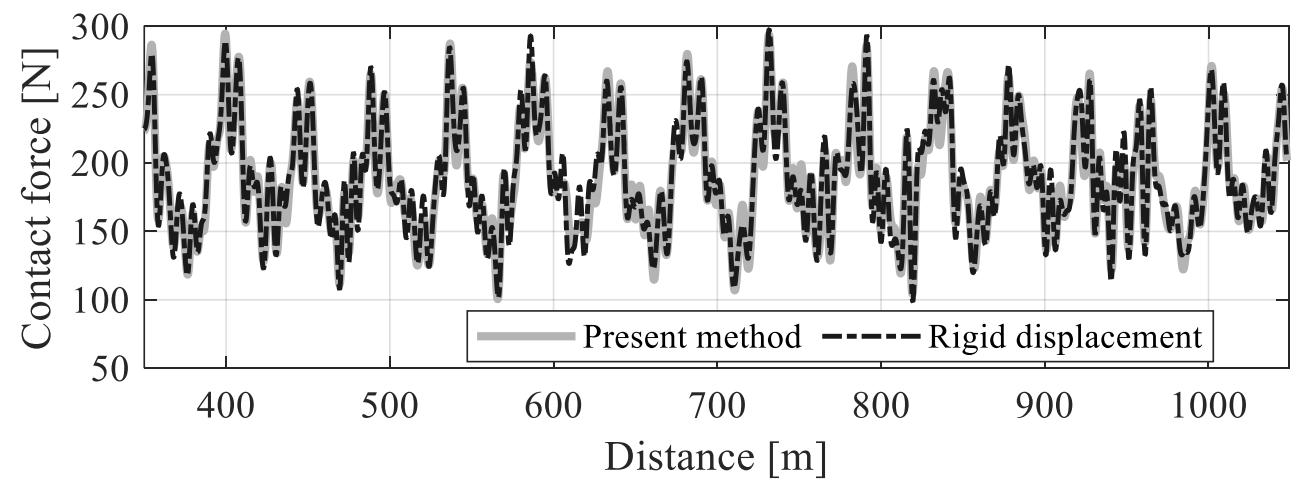

(b) 
Figure 22. Contact forces calculated by two methods at: (a) $300 \mathrm{~km} / \mathrm{h}$ and (b) $350 \mathrm{~km} / \mathrm{h}$

\section{Conclusions and Future Works}

Contact wire irregularities represent a realistic and common disturbance to the stable operation of the pantograph-catenary system. In this article, a novel methodology is proposed to build realistic catenary models using measured contact wire irregularities. By employing the TCUD method, the vertical position of the droppers and steady-arms can be correctly placed according to measured irregularity data.

The effect of contact wire irregularities on the pantograph-catenary dynamics is studied in several operation scenarios. The results indicate that the catenary irregularities are responsible for a higher amplitude of the contact force. Also, an increment in the contact force standard deviation is observed. The frequency analysis shows that the contact wire irregularities increase the PSD peaks of contact force at specific frequencies relevant to the span length and dropper spacing. This effect is equally noticeable at higher operating speeds.

When comparing with the previous method, which treats the contact wire irregularities as a series of hard spots, it is found that the former method exaggerates the negative effect of the contact wire irregularities, presenting more conservative results.

The measured contact wire irregularity levels considered in this work are small, and its effect is limited. In the future, more severe defects, local and singularities will be modelled and analysed in order to analyse their influence on train service.

\section{Acknowledgements}

This work was partially supported by the National Natural Science Foundation of China (U1734202). The authors express their gratitude to the Chinese Railway Corporation for the assistance to acquire the measurement data. This work was supported by FCT, through IDMEC, under LAETA, project UIDB/50022/2020.

\section{References}

[1] S. (Simon) Iwnicki, M. Spiryagin, C. Cole, T. (Timothy) McSweeney, Handbook of railway vehicle dynamics, n.d.

[2] S. Bruni, G. Bucca, M. Carnevale, A. Collina, A. Facchinetti, Pantograph-catenary interaction: recent achievements and future research challenges, Int. J. Rail Transp. 6 (2018) 57-82. https://doi.org/10.1080/23248378.2017.1400156.

[3] E. Arias, A. Alberto, J. Montesinos, T. Rojo, F. Cuartero, J. Benet, A mathematical model of the static pantograph/catenary interaction, Int. J. Comput. Math. 86 (2009) 333-340. https://doi.org/10.1080/00207160802044100.

[4] O. Lopez-Garcia, A. Carnicero, V. Torres, Computation of the initial equilibrium of railway overheads based on the catenary equation, Eng. Struct. 28 (2006) 13871394. https://doi.org/10.1016/j.engstruct.2006.01.007.

[5] M. Tur, E. García, L. Baeza, F.J. Fuenmayor, A 3D absolute nodal coordinate finite element model to compute the initial configuration of a railway catenary, Eng. Struct. 71 (2014) 234-243. https://doi.org/10.1016/j.engstruct.2014.04.015. 
[6] J.H. Seo, H. Sugiyama, A.A. Shabana, Three-dimensional large deformation analysis of the multibody pantograph/catenary systems, Nonlinear Dyn. 42 (2005) 199-215. https://doi.org/10.1007/s11071-005-2789-9.

[7] J. Ambrósio, J. Pombo, M. Pereira, P. Antunes, A. Mósca, Recent developments in pantograph-catenary interaction modelling and analysis, Int. J. Railw. Technol. 1 (2012) 249-278. https://doi.org/10.4203/ijrt.1.1.12.

[8] J. Ambrósio, J. Pombo, M. Pereira, P. Antunes, A. Mósca, A Computational Procedure for the Dynamic Analysis of the Catenary-Pantograph Interaction in High-Speed Trains, J. Theor. Appl. Mech. 50 (2012) 681-699.

[9] P. Antunes, A. Mósca, J. Ambrósio, J. Pombo, M. Pereira, Development of a computational tool for the dynamic analysis of the pantograph-catenary interaction for high-speed trains, Civil-Comp Proc. 99 (2012) 1-25.

[10] P. Antunes, J. Ambrósio, J. Pombo, Catenary finite element model initialization using optimization, in: Civil-Comp Proc., 2016. https://doi.org/10.4203/ccp.110.106.

[11] Y. Song, Z. Liu, H. Wang, X. Lu, J. Zhang, Nonlinear modelling of high-speed catenary based on analytical expressions of cable and truss elements, Veh. Syst. Dyn. 53 (2015) 1455-1479. https://doi.org/10.1080/00423114.2015.1051548.

[12] Y. Song, Z. Liu, H. Ouyang, H. Wang, X. Lu, Sliding mode control with PD sliding surface for high-speed railway pantograph-catenary contact force under strong stochastic wind field, Shock Vib. 2017 (2017) 4895321-1-16. https://doi.org/10.1155/2017/4895321.

[13] Y. Song, H. Ouyang, Z. Liu, G. Mei, H. Wang, X. Lu, Active control of contact force for high-speed railway pantograph-catenary based on multi-body pantograph model, Mech. Mach. Theory. 115 (2017) 35-59. https://doi.org/10.1016/j.mechmachtheory.2017.04.014.

[14] A. Facchinetti, S. Bruni, Hardware-in-the-loop hybrid simulation of pantographcatenary interaction, J. Sound Vib. 331 (2012) 2783-2797. https://doi.org/10.1016/j.jsv.2012.01.033.

[15] P. Nåvik, A. Rønnquist, S. Stichel, Variation in predicting pantograph-catenary interaction contact forces, numerical simulations and field measurements, Veh. $\begin{array}{lllll}\text { Syst. } & \text { Dyn. } & 55 & \text { (2017) }\end{array}$ https://doi.org/10.1080/00423114.2017.1308523.

[16] F. Vesali, M.A. Rezvani, H. Molatefi, M. Hecht, Static form-finding of normal and defective catenaries based on the analytical exact solution of the tensile EulerBernoulli beam, Proc. Inst. Mech. Eng. Part F J. Rail Rapid Transit. 233 (2019) 691-700. https://doi.org/10.1177/0954409718808990.

[17] O.V. Van, J.P. Massat, C. Laurent, E. Balmes, Introduction of variability into pantograph-catenary dynamic simulations, Veh. Syst. Dyn. 52 (2014) 1254-1269. https://doi.org/10.1080/00423114.2014.922199.

[18] M. Carnevale, A. Facchinetti, L. Maggiori, D. Rocchi, Computational fluid dynamics as a means of assessing the influence of aerodynamic forces on the mean contact force acting on a pantograph, Proc. Inst. Mech. Eng. Part F J. Rail Rapid Transit. 230 (2016) 1698-1713. https://doi.org/10.1177/0954409715606748.

[19] J. Pombo, J. Ambrosio, M. Pereira, F. Rauter, A. Collina, A. Facchinetti, Influence 
of the aerodynamic forces on the pantograph-catenary system for high-speed trains, Veh. Syst. Dyn. 47 (2009) 1327-1347. https://doi.org/10.1080/00423110802613402.

[20] Y. Song, Z. Liu, H. Wang, X. Lu, J. Zhang, Nonlinear analysis of wind-induced vibration of high-speed railway catenary and its influence on pantograph-catenary interaction, Veh. Syst. Dyn. 54 (2016) 723-747. https://doi.org/10.1080/00423114.2016.1156134.

[21] Y. Song, Z. Liu, H. Wang, J. Zhang, X. Lu, F. Duan, Analysis of the galloping behaviour of an electrified railway overhead contact line using the non-linear finite element method, Proc. Inst. Mech. Eng. Part F J. Rail Rapid Transit. 232 (2018) 2339-2352. https://doi.org/10.1177/0954409718769751.

[22] S. Avila-Sanchez, O. Lopez-Garcia, A. Cuerva, J. Meseguer, Assesment of the transverse galloping stability of a railway overhead located above a railway bridge, Int. J. Mech. Sci. 131-132 (2017) 649-662. https://doi.org/10.1016/j.ijmecsci.2017.07.024.

[23] H. Wang, A. Núñez, Z. Liu, Y. Song, F. Duan, R. Dollevoet, Analysis of the evolvement of contact wire wear irregularity in railway catenary based on historical data, Veh. Syst. Dyn. 56 (2018) 1207-1232. https://doi.org/10.1080/00423114.2017.1408919.

[24] A. Carnicero, J.R. Jimenez-Octavio, C. Sanchez-Rebollo, A. Ramos, M. Such, Influence of track irregularities in the catenary-pantograph dynamic interaction, J. Comput. Nonlinear Dyn. 7 (2012) 041015. https://doi.org/10.1115/1.4006735.

[25] S. Kulkarni, C.M. Pappalardo, A.A. Shabana, Pantograph/Catenary contact formulations, J. Vib. Acoust. Trans. ASME. $139 \quad$ (2017) 011010. https://doi.org/10.1115/1.4035132.

[26] J. Pombo, J. Ambrósio, Influence of pantograph suspension characteristics on the contact quality with the catenary for high speed trains, Comput. Struct. 110-111 (2012) 32-42. https://doi.org/10.1016/j.compstruc.2012.06.005.

[27] J. Pombo, J. Ambrosio, Environmental and track perturbations on multiple pantograph interaction with catenaries in high-speed trains, Comput. Struct. 124 (2013) 88-101. https://doi.org/10.1016/j.compstruc.2013.01.015.

[28] J. Pombo, P. Antunes, J. Ambrósio, A study on multiple pantograph operations for high-speed catenary contact, Civil-Comp Proc. 99 (2012).

[29] J. Pombo, P. Antunes, A Comparative Study between Two Pantographs in Multiple Pantograph High-Speed Operations, Int. J. Railw. Technol. 2 (2013) 83-108. https://doi.org/10.4203/ijrt.2.1.4.

[30] J. Pombo, J. Ambrósio, Multiple Pantograph Interaction With Catenaries in HighSpeed Trains, J. Comput. Nonlinear Dyn. 7 (2012). https://doi.org/10.1115/1.4006734.

[31] J. Ambrósio, J. Pombo, P. Antunes, M. Pereira, PantoCat statement of method, Veh. Syst. Dyn. $\quad 53$ (2015) 314-328. https://doi.org/10.1080/00423114.2014.969283.

[32] J. Ambrósio, J. Pombo, M. Pereira, Optimization of high-speed railway pantographs for improving pantograph-catenary contact, Theor. Appl. Mech. Lett. 3 (2013) 013006. https://doi.org/10.1063/2.1301306. 
[33] J. Ambrósio, F. Rauter, J. Pombo, M. Pereira, A Flexible Multibody Pantograph Model for the Analysis of the Catenary-Pantograph Contact, in: Comput. Methods Appl. Sci., 2011: pp. 1-27. https://doi.org/10.1007/978-90-481-9971-6_1.

[34] F. Rauter, J. Pombo, J. Ambrósio, M. Pereira, Multibody Modeling of Pantographs for Pantograph-Catenary Interaction, in: IUTAM Symp. Multiscale Probl. Multibody Syst. Contacts, Springer Netherlands, Dordrecht, 2007: pp. 205-226. https://doi.org/10.1007/978-1-4020-5981-0_20.

[35] J. Ambrósio, J. Pombo, F. Rauter, M. Pereira, A Memory Based Communication in the Co-simulation of Multibody and Finite Element Codes for PantographCatenary Interaction Simulation, in: Multibody Dyn., Springer Netherlands, Dordrecht, 2009: pp. 231-252. https://doi.org/10.1007/978-1-4020-8829-2_12.

[36] J. Ambrósio, F. Rauter, J. Pombo, M. Pereira, Dynamics of high-speed train pantograph-catenary co-simulation of finite element and multibody codes, in: AIP Conf. Proc., 2010. https://doi.org/10.1063/1.3452168.

[37] P. Antunes, H. Magalhães, J. Ambrósio, J. Pombo, J. Costa, A co-simulation approach to the wheel-rail contact with flexible railway track, Multibody Syst. Dyn. 45 (2019). https://doi.org/10.1007/s11044-018-09646-0.

[38] P. Antunes, J. Ambrósio, J. Pombo, A. Facchinetti, A new methodology to study the pantograph-catenary dynamics in curved railway tracks, Veh. Syst. Dyn. (2019). https://doi.org/10.1080/00423114.2019.1583348.

[39] A.W.C. Shing, P.P.L. Wong, Wear of pantograph collector strips, Proc. Inst. Mech. Eng. Part F J. Rail Rapid Transit. 222 (2008) 169-176. https://doi.org/10.1243/09544097JRRT156.

[40] S. Barmada, M. Tucci, F. Romano, Hierarchical Clustering applied to Measured Data Relative to Pantograph-Catenary Systems as a Predictive Maintenance Tool, Int. J. Railw. Technol. 3 (2014) 23-41. https://doi.org/10.4203/ijrt.3.4.2.

[41] W. Zhang, G. Mei, J. Zeng, A study of pantograph/catenary system dynamics with influence of presag and irregularity of contact wire, Veh. Syst. Dyn. 37 (2003) 593-604. https://doi.org/10.1080/00423114.2002.11666265.

[42] Y.H. Cho, K. Lee, Y. Park, B. Kang, K.N. Kim, Influence of contact wire pre-sag on the dynamics of pantographrailway catenary, Int. J. Mech. Sci. 52 (2010) 14711490. https://doi.org/10.1016/j.ijmecsci.2010.04.002.

[43] O. Vo Van, J.P. Massat, E. Balmes, Waves, modes and properties with a major impact on dynamic pantograph-catenary interaction, J. Sound Vib. 402 (2017) 5169. https://doi.org/10.1016/j.jsv.2017.05.008.

[44] Y. Qin, Y. Zhang, X.Q. Cheng, L.M. Jia, Z.Y. Xing, An analysis method for correlation between catenary irregularities and pantograph-catenary contact force, J. Cent. South Univ. 21 (2014) 3353-3360. https://doi.org/10.1007/s11771-0142309-5.

[45] H. Wang, Z. Liu, Y. Song, X. Lu, Z. Han, J. Zhang, Y. Wang, Detection of Contact Wire Irregularities Using a Quadratic Time-Frequency Representation of the Pantograph-Catenary Contact Force, IEEE Trans. Instrum. Meas. 65 (2016) 13851397. https://doi.org/10.1109/TIM.2016.2518879.

[46] A. Collina, F. Fossati, M. Papi, F. Resta, Impact of overhead line irregularity on current collection and diagnostics based on the measurement of pantograph 
dynamics, Proc. Inst. Mech. Eng. Part F J. Rail Rapid Transit. 221 (2007) 547559. https://doi.org/10.1243/09544097F02105.

[47] S. Bruni, J. Ambrosio, A. Carnicero, Y.H. Cho, L. Finner, M. Ikeda, S.Y. Kwon, J.-P. Massat, S. Stichel, M. Tur, W. Zhang, The results of the pantograph-catenary interaction benchmark, Veh. Syst. Dyn. 53 (2015) 412-435. https://doi.org/10.1080/00423114.2014.953183.

[48] EN 50318:2002, Railway Applications - Current Collection Systems - Validation of Simulation of the Dynamic Interaction Between Pantograph and Overhead Contact Line, (2002).

[49] Y. Song, Z. Liu, F. Duan, Z. Xu, X. Lu, Wave propagation analysis in high-speed railway catenary system subjected to a moving pantograph, Appl. Math. Model. 59 (2018) 20-38. https://doi.org/10.1016/j.apm.2018.01.001.

[50] H.T. Thai, S.E. Kim, Nonlinear static and dynamic analysis of cable structures, Finite Elem. Anal. Des. 47 (2011) 237-246. https://doi.org/10.1016/j.finel.2010.10.005.

[51] H.K. Kim, M.Y. Kim, Efficient combination of a TCUD method and an initial force method for determining initial shapes of cable-supported bridges, Int. J. Steel Struct. 12 (2012) 157-174. https://doi.org/10.1007/s13296-012-2002-1.

[52] Y. Song, Z. Liu, Z. Xu, J. Zhang, Developed moving mesh method for high-speed railway pantograph-catenary interaction based on nonlinear finite element procedure, Int. J. Rail Transp. 7 (2019) 173-190. https://doi.org/10.1080/23248378.2018.1532330.

[53] K.S. Kim, H.S. Lee, Analysis of target configurations under dead loads for cablesupported bridges, Comput. Struct. $79 \quad$ (2001) 2681-2692. https://doi.org/10.1016/S0045-7949(01)00120-1.

[54] EN 50367:2012+A1:2016, EN 50367. Railway applications - Current collection systems - Technical criteria for the interaction between pantograph and overhead line., 2016. 